\title{
ANALYTICAL TOOLS FOR MEASURING POVERTY DYNAMICS: AN APPLICATION USING PANEL DATA IN THE PHILIPPINES
}

Arturo Martinez Jr.

NO. 477

March 2016
ADB ECONOMICS WORKING PAPER SERIES 


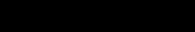

\section{ADB Economics Working Paper Series}

\section{Analytical Tools for Measuring Poverty Dynamics: An Application Using Panel Data in the Philippines}

Arturo Martinez Jr.

No. 477 | March 2016
Arturo Martinez Jr. (amartinezjr@adb.org) is Statistician at the Development Economics and Indicators Division, Economic Research and Regional Cooperation Department.

This study was carried out under Regional Technical Assistance (RETA) 8522: The Urbanization-PovertyInequality Triangle in Asia and the Pacific. The author benefited from the insightful comments of Rana Hasan, Richard Bolt, Joven Balbosa, Natalie Chun, Lakshman Rao, Mark Western, Michele Haynes, and Wojtek Tomaszewski. The author is also grateful to the Philippine Statistics Authority for providing the dataset used in this study. 
Asian Development Bank

6 ADB Avenue, Mandaluyong City

1550 Metro Manila, Philippines

www.adb.org

(C) 2016 by Asian Development Bank

March 2016

ISSN 2313-6537 (Print), 2313-6545 (e-ISSN)

Publication Stock No. WPS167918-2

The views expressed in this paper are those of the author and do not necessarily reflect the views and policies of the Asian Development Bank (ADB) or its Board of Governors or the governments they represent.

ADB does not guarantee the accuracy of the data included in this publication and accepts no responsibility for any consequence of their use.

By making any designation of or reference to a particular territory or geographic area, or by using the term "country" in this document, $A D B$ does not intend to make any judgments as to the legal or other status of any territory or area.

Note: In this publication, "\$” refers to US dollars.

The ADB Economics Working Paper Series is a forum for stimulating discussion and eliciting feedback on ongoing and recently completed research and policy studies undertaken by the Asian Development Bank (ADB) staff, consultants, or resource persons. The series deals with key economic and development problems, particularly those facing the Asia and Pacific region; as well as conceptual, analytical, or methodological issues relating to project/program economic analysis, and statistical data and measurement. The series aims to enhance the knowledge on Asia's development and policy challenges; strengthen analytical rigor and quality of ADB's country partnership strategies, and its subregional and country operations; and improve the quality and availability of statistical data and development indicators for monitoring development effectiveness.

The ADB Economics Working Paper Series is a quick-disseminating, informal publication whose titles could subsequently be revised for publication as articles in professional journals or chapters in books. The series is maintained by the Economic Research and Regional Cooperation Department. 


\section{CONTENTS}

TABLES AND FIGURES

ABSTRACT V v v v v v

$\begin{array}{ll}\text { I. INTRODUCTION } & 1\end{array}$

II. STYLIZED FACTS ABOUT INTERTEMPORAL POVERTY IN THE PHILIPPINES 2

III. METHODOLOGY 3

A. Measuring Intertemporal Poverty Using the Components Approach 3

B. Measuring Intertemporal Poverty Using the Spells Approach 5

C. Examining the Profile of Persistently and Transiently Poor 7

$\begin{array}{lll}\text { IV. } & \text { DATA } & 8\end{array}$

$\begin{array}{llr}\text { V. } & \text { EMPIRICAL RESULTS } & 9\end{array}$

A. Intertemporal Poverty in the Philippines 9

B. Where are the Persistently and Transiently Poor? $\quad 15$

C. Who are the Persistently and Transiently Poor? 21

VI. ROBUSTNESS CHECK: SWITCHING FROM 2005 TO 2011

PURCHASING POWER PARITY

$\begin{array}{llr}\text { VII. SUMMARY } & 27\end{array}$

$\begin{array}{lr}\text { REFERENCES } & 29\end{array}$ 


\section{TABLES AND FIGURES}

\section{TABLES}

1 Representativeness of the Longitudinal Subsample

2 Cross-Sectional Measures of Poverty in the Philippines, 2003-2009

3 Population Share by Intertemporal Poverty Status

4 Regression Coefficients of Multinomial Logistic Models for Intertemporal Poverty in the Philippines Using Three Waves of Panel Data: 2003, 2006, and 2009

\section{FIGURES}

$1 \quad$ Headcount Poverty Curve, 2009

2 Poverty Rate by Region, 2003, 2006, 2009 


\begin{abstract}
This study reviews two methods of measuring poverty dynamics. The components approach uses the longitudinally averaged income to determine whether a household is chronically poor or not. On the other hand, the spells approach counts the number of poverty episodes experienced by a household. Using panel data from the Philippines, we examine the differences between these analytical methods of measuring chronic and transient poverty. Furthermore, the study also examines the sensitivity of estimates of poverty dynamics to measurement parameters. While I find that both the components and spells approaches suggest that most poverty experiences of Filipino households were persistent, my robustness analysis reveals that the relative importance of persistent and transient poverty are sensitive to the type of poverty measure used and the poverty line specified. In particular, the relative importance of transient poverty increases dramatically as the poverty line decreases or as the poverty measure becomes more sensitive to the welfare of the poorest of the poor.
\end{abstract}

Keywords: persistent poverty, Philippines, transient

JEL codes: D31, I32, O15 


\section{INTRODUCTION}

A person's intertemporal poverty experience can either be persistent (chronic) or transient. Persistent poverty could be further transmitted across generations giving way to vicious cycles of socioeconomic deprivation that are harmful to a country's long-term growth prospects. Differentiating between the alternative poverty scenarios is of uttermost importance, as the policy interventions necessary to ameliorate these different types of disadvantage may be very different. Therefore, when outlining intervention programs, it is important that policy planners recognize that the disadvantaged are not a homogeneous population and that their varying circumstances lead to varying needs. For instance, providing social safety nets to minimize the adverse impact of socioeconomic shocks may not be an optimal strategy to reduce disadvantage amongst people who have experienced uninterrupted, even intergenerational, spells of poverty. Similarly, providing long-term social assistance to those who are transiently disadvantaged may not be cost-effective. The key message is that no poverty and disadvantage reduction programs will serve as a "one-size-fits-all" policy lever, and hence examining the temporal patterns of disadvantage can guide efficient and cost-effective policy-making decisions.

Poverty reduction is explicitly articulated as a goal in the Philippines' medium-term development plan. However, official headline statistics of poverty in the country are usually presented as a cross-sectional snapshot picture of disadvantage (NSCB 2013). These static measures describe poverty in the country as a one-time event, and ignore the persistence and recurrence of poverty over time. To address these limitations, Bayudan-Dacuycuy and Lim (2013), and Reyes et al. (2011) recently attempted to incorporate a longitudinal perspective in the analysis of the country's poverty using panel data derived from the redesigned Family Income and Expenditure Survey. Their results suggest that poverty in the Philippines is mostly persistent in nature. However, they fall short in examining the sensitivity of their estimates to different estimation methodologies. For instance, both studies used the official poverty lines compiled by the government. However, its use remains debatable because the official poverty thresholds are based on different regional food menus which tend to make the resulting estimates inconsistent across regions (Bersales 2009). In addition, both studies used the spells approach which fails to account the possibility that households can "borrow" income from different time periods through savings.

The main objective of this study is to examine the robustness of estimates using alternative methodologies for measuring intertemporal poverty. This is important because previous studies suggest that poverty estimates depend highly on the methodological approach used (Foster et al. 2013, Haughton and Khandker 2009). Without checking the robustness of estimates to methodologies, it is hard to establish the quantitative importance of findings from a specific study. On the other hand, knowledge on the robustness of estimates provides more nuanced insight into poverty and disadvantage patterns which in turn, could help researchers to communicate poverty estimates better

to its key stakeholders. In order to provide a broader overview of intertemporal poverty in the Philippines, this study addresses the following substantive and methodological questions:

\section{Methodological}

(i) Are the observed patterns sensitive to the estimation methodology, poverty lines and types of poverty index?

(ii) How robust are the poverty rankings to the parameters used in the estimation process? 


\section{Substantive}

(iii) Is poverty in the Philippines characterized by long episodes of poverty spells or transitory movements around the poverty line?

(iv) Where are the persistently and transiently poor located?

(v) Aside from geography, what are the characteristics of persistently and transiently poor?

Following the introduction, a brief overview of the intertemporal poverty literature in the Philippines is provided. The third section describes the different methodologies for measuring and examining the profile of intertemporal poverty. The fourth section describes the main data source used in the succeeding analyses. The empirical results of the analysis are discussed in the fifth section, while the last section summarizes the main findings and provides a conclusion.

\section{STYLIZED FACTS ABOUT INTERTEMPORAL POVERTY IN THE PHILIPPINES}

For decades, the Philippines has been working to reduce poverty by implementing a multitude of antipoverty programs which aim to improve the quality of life of the poor (Bayudan-Dacuycuy and Lim 2013, ADB 2005, 2009). From 1986 to 1992, the Aguino administration implemented three major intervention programs which include the Tulong sa Tao (Help for the People), the Comprehensive Agrarian Reform, and the Community Employment and Development. From 1992 to 1998, the Ramos administration implemented the Social Reform Agenda which focused on the development of the 20 poorest provinces and the poorest sectors. From 1998 to 2001, the Estrada Administration launched the Lingap Para sa Mahirap (Care for the Poor) which provided assistance to the poorest families from each local government unit. From 2006 to 2010, the Arroyo administration started the Kapit Bisig Laban sa Kahirapan (Linking Arms Against Poverty Program) which offered socioeconomic services to the poor. The current Aquino administration is implementing the Social Reform Program which provides conditional cash transfers to families that satisfy a certain criteria. These programs have been associated with reduction in the number of poor in both absolute and relative terms. For instance, the proportion of the population living below $\$ 2$ a day dropped from $62 \%$ in 1985 to $42 \%$ in 2009 .

The pace of poverty reduction in the Philippines, however, is slower compared to other developing countries in Southeast Asia, even during episodes of faster economic growth over the past decade (ADB 2005, 2009). For instance, \$2 headcount poverty rate barely dropped from $45 \%$ in 2003 to $44 \%$ in 2009 despite the country's gross domestic product growing at an average rate of $3 \%$ per year (WDI 2013). Reyes et al. (2011) identified that one of the main institutional bottlenecks that has contributed to this problem is that the poverty reduction programs are not well-targeted and tend to discount the heterogeneous needs of the poor. For instance, past programs had overlooked the differential needs of the persistently and transiently poor. This issue is often attributed to the lack of empirical data. For many years, socio-economic planners had to rely on poverty data collected from cross-sectional surveys. It was only in 2003 when the Family Income and Expenditure Survey (FIES), the data source of official poverty estimates, was redesigned to collect nationally-representative panel data. More recently, Bayudan-Dacuycuy and Lim (2013) and Reyes et al. (2011) used the panel data from the redesigned FIES to examine the magnitude of persistent and transient poverty in the Philippines. Reyes et al. (2011) found that small changes in cross-sectional poverty do not necessarily imply minimal movements into and out of poverty while Bayudan-Dacuycuy and Lim (2013) surmised that poverty in the country is largely comprised of persistent poverty. 
Although these studies have provided a more dynamic perspective of poverty, they have some limitations. First, they did not examine how their results could change when they vary the estimation methodology, poverty line or poverty index. This makes it difficult to gauge whether the observed trends can be linked with meaningful interpretations or are just driven by the measurement approaches that they used. In general, examining robustness of the statistical results is important for both methodological and substantive reasons. The existing literature suggests that the estimates of intertemporal poverty may vary significantly depending on the measurement parameters (Christiaensen and Shorrocks 2012, McCulloch and Baulch 1999, Jalan and Ravallion 1998). If robustness of the parameter estimates is not guaranteed, it is possible that the poverty levels reported are arbitrary leading to inaccurate interpretations and outcomes.

This study extends the existing literature using different analytical tools and measurement parameters in the estimation of intertemporal poverty. Unlike previous studies that used a spells approach (i.e., Reyes et al. 2011, Bayudan-Dacuycuy and Lim 2013) and focused on frequency of poverty episodes over time only, this study also adopts the components approach which estimates intertemporal poverty based on a household's average income over time. In addition, I measure the incidence, depth and severity of intertemporal poverty in the Philippines using four different sets of poverty lines, an exercise that has not been carried out in previous research.

\section{METHODOLOGY}

\section{A. Measuring Intertemporal Poverty Using the Components Approach}

The components approach can be traced back to the permanent income hypothesis proposed by Friedman which states that over a person's lifecycle, each has his/her own permanent income stream but it can have short-term transitory fluctuations from time to time (Friedman 1957). The main interest of the components approach lies on disentangling the contribution of the short-term and long-term components to a person's income intertemporal poverty status.

\section{Jalan and Ravallion (1998) Approach}

Jalan and Ravallion (JR) (1998) proposed using the longitudinal average as an estimate of permanent income. In particular, suppose $\bar{Y}_{i}=\frac{\sum_{t=1}^{T} Y_{i t}}{T}$ and $g_{i}=\max (1, Y i t)$ and $\bar{g}_{i}=\max \left(1, \bar{Y}_{i}\right)$ where $Y_{i t}$ is used to denote the $i^{t h}$ person's income at time $t$, normalized by the poverty line $z$. In other words, $Y_{i t}$ is equal to the $Y_{i t}$ used in the previous section divided by the poverty line. The measures of total poverty and poverty persistence are given by (1) and (2), respectively. On the other hand, transient poverty is estimated by subtracting poverty persistence from total poverty (3).

$$
\begin{gathered}
P_{\alpha}^{\text {total }}=\frac{\sum_{i=1}^{N} \sum_{t=1}^{T} g_{i t}^{\alpha}}{N T} \\
P_{\alpha}^{\text {persist }}=\frac{\sum_{i=1}^{N} \bar{g}_{i}^{\alpha}}{N} \\
P_{\alpha}^{\text {transient }}=P_{\alpha}-P_{\alpha}^{\text {persist }}
\end{gathered}
$$


These measures are analogous to the class of poverty indices proposed by Foster, Greer, and Thorbecke (1984). Hence, when $\alpha=0$, they measure the incidence of intertemporal poverty, depth when $\alpha=1$, and severity when $\alpha=2$. If all units have longitudinal average incomes that exceed the poverty line $z$, but income in some time periods fall below $z, P_{\alpha}^{\text {persist }}$ will be equal to 0 , while $P_{\alpha}^{\text {transient }}$ will be equal to $P_{\alpha}$. On the other hand, if all units have longitudinal average income falling below $z$, both $P_{\alpha}^{\text {Total }}$ and $P_{\alpha}^{\text {persist }}$ will take a value of 1 and consequently, $P_{\alpha}^{\text {transient }}$ will be 0 .

\section{Duclos, Araar, and Giles (2010) Approach}

Like Jalan and Ravallion (1998), Duclos, Araar, and Giles (DAG) (2010) also proposed using longitudinal average income as an estimate of permanent income. However, unlike the JR approach, the DAG approach differentiates a poor person whose income consistently fell below the poverty line throughout the observation period from a person with the same longitudinal average income but experienced both poverty and nonpoverty. By doing so, the DAG approach takes into account a person's risk aversion to unexpected income fluctuations. This is consistent with the notion that a person's (economic) disutility tends to increase as the variation in their income stream increases which also leads to higher transient poverty (Gottschalk 1982). The DAG approach entails computing the variability-adjusted poverty status of each person (4). The parameter $\alpha \geq 1$ represents a person's level of risk aversion to income variations wherein a value of unity means that the person is risk neutral. On the other hand, the risk premium that person $i$ would be willing to pay to be able to remove the variability in its poverty gap status is given by $\gamma_{\alpha}\left(g_{i}\right)(5)$. Under the DAG approach, transient poverty is defined as the total cost that will be incurred due to variability in poverty gaps over time, while total poverty is the sum of the average poverty gap in the population, the cost of inequality in equally distributed poverty gaps among individuals, and transient poverty. ${ }^{1}$

$$
\begin{gathered}
P_{i \alpha}\left(g_{i}\right)^{\frac{1}{\alpha}}=\left(\frac{\sum_{i=1}^{T} g_{i t}^{\alpha}}{T}\right)^{\frac{1}{\alpha}} \\
\gamma_{\alpha}\left(g_{i}\right)=P_{i \alpha}\left(g_{i}\right)-P_{i 1}\left(g_{i}\right) \\
\Gamma_{\alpha}^{T}(g)=\frac{\sum_{i=1}^{N} \gamma_{\alpha}\left(\mathrm{g}_{\mathrm{i}}\right)}{N} \\
\Gamma_{\alpha}\left(\mathrm{P}_{\alpha}\right)=\left(\frac{\sum_{i=1}^{N} \mathrm{P}_{\mathrm{i} \alpha}\left(\mathrm{g}_{i}\right)^{\alpha}}{N}\right)^{1 / \alpha} \\
C_{\alpha}\left(\mathrm{P}_{\alpha}\right)=\Gamma_{\alpha}\left(\mathrm{P}_{\alpha}\right)-\Gamma_{1}\left(\mathrm{P}_{\alpha}\right) \\
\mathrm{P}_{\alpha}^{\text {total }}=\Gamma_{1}(\mathrm{~g})+C_{\alpha}\left(\mathrm{P}_{\alpha}\right)+\Gamma_{\alpha}^{T}(g) \\
\mathrm{P}_{\alpha}^{\text {transient }}=\frac{\sum_{i=1}^{N} \gamma_{\alpha}\left(g_{i}\right)}{N} \\
\mathrm{P}_{\alpha}^{\text {chronic }}=\mathrm{P}_{\alpha}^{\text {total }}-\mathrm{P}_{\alpha}^{\text {transient }}
\end{gathered}
$$

\footnotetext{
1 When a household is risk neutral $(\alpha=1)$, transient poverty will be equal to 0 .
} 
Although the JR and DAG approaches both fall under the components framework of measuring poverty dynamics, the two approaches have major differences. For instance, while the income movements above the poverty line influences a person's persistent poverty status under the JR approach, the same cannot be said about the DAG approach because it censors income movements at the poverty line. In other words, under the JR approach, a person experiencing numerous episodes of poverty may still be considered not persistently poor if his/her income for at least one time period is high enough to make the longitudinally averaged income exceed the poverty line. On the other hand, since only poverty gaps are considered when using the DAG approach, high incomes for few time periods cannot compensate for the numerous episodes that a person spent in poverty. Another important difference between the two approaches lies on how transient poverty is conceptualized. In the JR approach, transient poverty is simply the difference between total poverty and poverty persistence whereas under the DAG approach, transient poverty is intimately linked with the level of risk aversion a person has toward income fluctuations.

\section{B. Measuring Intertemporal Poverty Using the Spells Approach}

Unlike the components approach, the spells approach treats a person's poverty status in each time period, independently. The spells approach is consistent with the arguments presented by Jappelli (1990) stating that it is not safe to assume that individuals can "borrow" income from different time periods when there are variations in the liquidity constraints over time.

\section{Conventional Spells Approach}

The conventional spells approach entails counting the number of time periods when the observed income of each person fell below the poverty line. Then, a specific frequency threshold $\tau \leq T$ is used to distinguish transient from persistent poverty (14). For example, in the study of Gaiha and Deolalikar (1993) covering 9 years of data, the authors defined persistent poverty as those whose income fell below the poverty line for at least 5 years. On the other hand, in a study covering 3 survey years, Reyes et al. (2011) defined persistent poverty as those who experienced income shortfall for at least 2 years.

$$
\begin{gathered}
P^{\text {persist }}=\frac{\sum_{i=1}^{N} V_{i}}{N} \\
P^{\text {transient }}=\frac{\sum_{i=1}^{N}\left(1-V_{i}\right)}{N}
\end{gathered}
$$

where

$$
V_{i}=\left\{\begin{array}{l}
1 \text { if } \sum_{t=1}^{T} I\left(Y_{i t}<1\right)>\tau \\
0, \text { otherwise }
\end{array}\right.
$$

The intertemporal poverty measures presented in (12) and (13) have several limitations. First, they only estimate the number of persistently and transiently poor and do not provide any information about the depth and severity of intertemporal poverty. These measures are not also sensitive to the duration of poverty. For example, a persistently poor person who stays in poverty for an additional year because of lower income, will not reflect an increase in $P^{\text {persist }}$. Similarly, a transiently poor person who stays in poverty for an additional year will not increase $P^{\text {transient }}$ as long as the time spent in poverty does not exceed $\tau$. 


\section{Foster (2009) Approach}

To address the limitations of the conventional spells-based measures of poverty dynamics, Foster (2009) introduced a class of intertemporal poverty measures that are sensitive to poverty duration and can be used to estimate incidence (15), depth (16), and severity of intertemporal poverty (17). The proposed measures are provided below:

$$
\begin{gathered}
K_{0}=H D \\
K_{1}=H D G \\
K_{2}=H D G S
\end{gathered}
$$

where $H$ is the proportion of the persistently poor persons (i.e., $H=P^{\text {persist }}$ ), $D$ is the average duration that persistently poor persons spent in poverty, $G$ is the average proportional income shortfall of persistently poor persons, and $S$ is the average squared proportional income shortfall of persistently poor persons. From this, it is straightforward to estimate transient poverty. First, I estimate $K(Y, z, \tau=$ 0 ) using the same formula. In other words, all poverty spells are accounted for. Transient poverty is then estimated by subtracting poverty persistence from total poverty.

Although the Foster approach takes into account the number of episodes spent in poverty when measuring poverty dynamics, it does not take into consideration whether some poverty episodes occurred consecutively. Hence, it fails to consider that continuous episodes of poverty can be more harmful than the same number of periods spent in poverty but spread in between several episodes of nonpoverty (Bane and Ellwood 1986, and Jappelli 1990). ${ }^{2}$

\section{Gradin and del Rio (2012) Approach}

Gradin and del Rio (2012) noted that many of the techniques discussed above fail to satisfy several properties of an ideal intertemporal poverty measure. ${ }^{3}$ For instance, the conventional spells approach and Foster approach violates the poverty duration sensitivity property because these approaches only take into account the number of poverty episodes within the observation period but not the duration spent in consecutive episodes of poverty. On the other hand, components-based measures such as the JR approach violate the intertemporal focus, poverty spell duration sensitivity, and regressive transfer axioms because periods of high income compensate for periods of low income. To address this issue, Gradin and del Rio (2012) proposed a class of intertemporal poverty measures which circumvent these limitations.

$$
p_{i}^{G R}\left(Y_{i} ; z\right)=\frac{1}{T} \sum_{t=1}^{T} g_{i t}^{\gamma} w_{i t}^{\beta}
$$

2 This is consistent with the state dependence hypothesis about poverty which states that the longer a household stays in poverty, the lower the chance of escaping it.

3 According to Gradin and del Rio (2012), the ideal properties of intertemporal poverty measure includes continuity, focus, monotonicity, scale invariance, duration sensitivity, and transfer axioms. 
such that

$$
\begin{gathered}
g_{i t}^{\gamma}=\left\{\begin{array}{c}
\left(\frac{z_{i}-Y_{i t}}{z_{i}}\right)^{\gamma} \text { if } Y_{i t}<z_{t} \\
\text { otherwise }
\end{array}\right. \\
w_{i t}^{\beta}=\left(\frac{s_{i t}}{T}\right)^{\beta} \\
P_{G R}(Y ; z)=\left\{\begin{array}{c}
\frac{1}{N} \sum_{i=1}^{N} p_{i}^{G R}\left(Y_{i} ; z\right) \\
\frac{q}{N} \quad \text { if } \alpha>0
\end{array}\right.
\end{gathered}
$$

The term $\gamma$ is analogous to the parameter used in the conventional poverty measures proposed by Foster, Greer, and Thorbecke (1984) which indicates index's sensitivity to the depth of poverty. The parameter $\beta$ indicates the level of sensitivity of the poverty measure to the duration of the poverty spell. In particular, higher values of $\beta$ provide more penalty to longer episodes of poverty.

\section{Examining the Profile of Persistently and Transiently Poor}

The second part of this study differentiates the characteristics of the persistently poor, transiently poor and nonpoor by estimating multinomial logistic models. The dependent variable measures the intertemporal poverty status of each household and takes two forms as shown in (22). The first form evaluates poverty status using the components approach, while the second form uses the spells approach. Under the components approach, a household is considered persistently poor if its longitudinally averaged income falls below the specified poverty line, transiently poor if its longitudinally averaged income is higher than the poverty line but at least one of its cross-sectional incomes fell below the poverty line, and nonpoor if the household never experienced income shortfall (below the poverty line). Under the spells approach, a household is considered persistently poor if at least two of it cross-sectional incomes fell below the poverty line, transiently poor if only one of its cross-sectional incomes fell below the poverty line, and nonpoor if the household never experienced income shortfall. Each outcome of interest is regressed on several household characteristics such as the human capital available to the household, assets held by the household, access to basic services, and geographic characteristics in the initial time period. Changes in these factors are also included as explanatory variables in the model as shown in (22). ${ }^{4}$

$$
\begin{aligned}
\text { (a) } W_{1}= & \begin{cases}0, \text { hhld is nonpoor } & \text { where poverty status is gauged based on } \\
1, \text { hhld is persistently poor } & \text { longitudinally averaged income } \\
2, \text { hhld is transiently poor } & \text { where poverty status is gauged based on the }\end{cases} \\
\text { (b) } W_{2}= \begin{cases}0, \text { hhld is nonpoor } & \text { number of episodes spent in poverty } \\
1, \text { hhld is persistently poor } & \text {, hhld is transiently poor }\end{cases} & W_{i}=\beta_{1} \text { Human Capital }+\beta_{2} \text { Assets }+\beta_{3} \text { Access to Services }+\beta_{4} \text { Geography } \\
+ & \beta_{5} \Delta \text { Human Capital }+\beta_{6} \Delta \text { Assets }+\beta_{7} \Delta \text { Access to Services }+\varepsilon_{i t}
\end{aligned}
$$

4 While discrete-time hazard models also suit the main objective of the study which is to identify the determinants of poverty exit and reentry rates, the limited number of data points complicates the estimation of a discrete-time hazard model in this context. 


\section{DATA}

The principal measure of living standards used in this study is the inflation- and spatially adjusted per capita household consumption expenditure derived from the FIES, ${ }^{5}$ a triennial income and consumption household survey conducted by the Philippine National Statistics Office (NSO). Technically, FIES is a cross-sectional survey but starting in 2003, it has been redesigned to follow the 2003 Master Sample Design for Philippines Household Surveys. ${ }^{6}$ In each wave since 2003, FIES collects information from approximately 44,000 households that produces reliable estimates at the national and (geographic) regional levels. Moreover, to provide longitudinal data, the 2003 Master Sample Design provides a scheme where random subsample of households used in previous waves of FIES are rotated back for the succeeding waves (Ericta and Fabian 2009). In this study, I use the data from the 6,519 households that appeared in all three waves.

Table 1 compares the household expenditure distribution between the full cross-sectional sample with the longitudinal subsample using two indicators: overall mean consumption expenditure and Gini index. I note that these measures tend to be underestimated in the longitudinal subsample, especially when I look at households that appear in all three waves. To adjust for this potential bias, I introduce weights for attrition by estimating logistic models of the probability of appearing in 2003, 2006, and 2009 waves using income, age of household head, sex of household head, and urbanity as controls. The inverse of the predicted probabilities are multiplied to the existing survey weights. The corresponding estimates of mean expenditure and inequality using the adjusted survey weights are provided in the last three rows of Table 1. I find that the adjusted estimates for the longitudinal subsample are much closer to the estimates based on the full cross-sectional sample than the unadjusted estimates. Moreover, the differences between the full cross-sectional estimates and the adjusted longitudinal subsample estimates do not seem to be statistically significant. In all succeeding analyses, we used the bias-adjusted weights.

I use four sets of poverty lines, three of them are absolute poverty thresholds in the sense that the poverty status of a household does not depend on the incomes of other households. These are the $\$ 1.25 /$ day ( $\$ 456 /$ year), $\$ 2 /$ day ( $\$ 729.6 /$ year) poverty line proposed by the World Bank (expressed in 2005 purchasing power parity [PPP]) and the official poverty line compiled by the Philippine National Statistical Coordination Board. Unlike the $\$ 1.25$ and $\$ 2$-a-day poverty lines which take a single scalar value, the national poverty line differs across provinces. On the other hand, the half-of-median threshold is a relative poverty line in the sense that it implicitly depends on the distribution of the incomes of all households. Because the half-of-median yields the smallest poverty threshold followed by the official poverty line, while the $\$ 2$-a-day produces the highest poverty threshold, one would expect that poverty estimates will be highest based on the $\$ 2$-a-day poverty line. Thus, the $\$ 1.25 /$ day and $\$ 2 /$ day-based estimates can be considered as lower and upper bound of poverty, respectively.

5 The income measure is adjusted to account for differences in regional prices using the spatial price indices compiled by Sta. Ana and Varona (2012). In particular, the per capita household consumption expenditure is expressed based on the prices in the National Capital Region.

6 In repeated cross-section surveys, a master sample is a sample from which sub-samples can be drawn for the purpose of more than one (household) survey or more than one round of survey. 
Table 1: Representativeness of the Longitudinal Subsample

\begin{tabular}{|c|c|c|c|c|c|c|}
\hline \multirow[b]{2}{*}{ Time period } & \multicolumn{2}{|c|}{2003} & \multicolumn{2}{|c|}{2006} & \multicolumn{2}{|c|}{2009} \\
\hline & $\begin{array}{l}\text { Mean } \\
\text { Std Error }\end{array}$ & $\begin{array}{l}\text { Gini } \\
\text { Std Error }\end{array}$ & $\begin{array}{l}\text { Mean } \\
\text { Std Error }\end{array}$ & $\begin{array}{c}\text { Gini } \\
\text { Std Error }\end{array}$ & $\begin{array}{l}\text { Mean } \\
\text { Std Error }\end{array}$ & $\begin{array}{c}\text { Gini } \\
\text { Std Error }\end{array}$ \\
\hline \multicolumn{7}{|l|}{ Full sample } \\
\hline \multirow{2}{*}{ Cross-sectional sample } & $1,258.53$ & 0.440 & $1,228.05$ & 0.441 & $1,286.33$ & 0.430 \\
\hline & 9.43 & 0.002 & 10.88 & 0.003 & 12.79 & 0.002 \\
\hline \multicolumn{7}{|l|}{$\begin{array}{l}\text { Longitudinal subsample (before } \\
\text { weight adjustment }\end{array}$} \\
\hline \multirow{2}{*}{2003,2006, and 2009} & $1,138.48$ & 0.428 & $1,132.76$ & 0.438 & $1,159.69$ & 0.414 \\
\hline & 28.32 & 0.006 & 28.80 & 0.005 & 25.86 & 0.004 \\
\hline \multicolumn{7}{|l|}{$\begin{array}{l}\text { Longitudinal subsample (after } \\
\text { weight adjustment) }\end{array}$} \\
\hline \multirow{2}{*}{2003,2006, and 2009} & $1,234.84$ & 0.431 & $1,233.27$ & 0.445 & $1,267.91$ & 0.423 \\
\hline & 31.30 & 0.006 & 32.57 & 0.006 & 29.21 & 0.005 \\
\hline
\end{tabular}

Source: Author's computations using FIES 2003, 2006, and 2009.

\section{EMPIRICAL RESULTS}

\section{A. Intertemporal Poverty in the Philippines}

I start with a presentation of cross-sectional estimates of headcount poverty rates, poverty gap, severity of poverty, and Watts index. Depending on the poverty line used, it is estimated that about $13 \%$ to 39\% of the population can be considered poor in 2009 (Figure 1). Furthermore, the estimates presented in Table 2 suggest that the poverty gap or average income shortfall is about 3\% to 13\%, while the severity of poverty or average squared income shortfall is roughly $1 \%$ to $5 \%$ of the poverty line. If all (per capita) household incomes were increased by $2 \%$ per year, the estimates of Watts index suggest that poverty is expected to be eradicated after 8 to 9 years from 2009. Table 2 and Figure 2 also indicates that poverty in the Philippines has a remarkable geographic feature. In particular, the proportion of poor in rural areas (mostly found in the southern part of the Philippines) is about two to four times the headcount poverty rate in urban areas. The magnitude of income shortfall and the inequality among the poor are also significantly higher in rural areas than in urban areas. Hence, it is not surprising to note that from 2009, it will take about 13 years for all households in rural areas to exit the $\$ 2 /$ day poverty compared to the 4 years needed for households from urban areas to accomplish the same feat, assuming a uniform $2 \%$ annual income growth.

Although the numbers presented in Table 2 are useful for gauging how significant poverty is in the Philippines, they provide limited information about poverty dynamics over time. For instance, the slight increase in poverty from 2003 to 2006 and minimal reduction between 2006 and 2009, do not readily imply limited movements into and out of poverty (Reyes et al. 2011). The next sections examine the patterns of intertemporal poverty.

7 This is computed by dividing the value of the Watts index by the expected income growth rate. For example, the Watts index value in 2009 using the $\$ 2 /$ day poverty line is 16.64 . Dividing this by an assumed annual income growth rate of $2 \%$ will yield 8.32. This means that, under the assumption that all incomes grow at a uniform rate of $2 \%$ per year, $\$ 2$ poverty rate will be eradicated after 8.32 years. 
Table 2: Cross-Sectional Measures of Poverty in the Philippines, 2003-2009

\begin{tabular}{|c|c|c|c|c|c|c|c|c|c|}
\hline \multirow[b]{2}{*}{ Poverty Measure } & \multicolumn{3}{|c|}{2003} & \multicolumn{3}{|c|}{2006} & \multicolumn{3}{|c|}{2009} \\
\hline & $\mathrm{PHI}$ & Urban & Rural & $\mathrm{PHI}$ & Urban & Rural & $\mathrm{PHI}$ & Urban & Rural \\
\hline \multicolumn{10}{|l|}{$\begin{array}{l}\$ 1.25 / \text { day Poverty } \\
\text { Line }\end{array}$} \\
\hline \multicolumn{10}{|l|}{ Headcount } \\
\hline poverty rate & 18.29 & 6.54 & 29.67 & 19.25 & 7.32 & 30.80 & 15.40 & 6.54 & 23.97 \\
\hline Poverty gap & 4.47 & 1.19 & 7.65 & 4.74 & 1.53 & 7.85 & 3.15 & 1.17 & 5.07 \\
\hline Severity of poverty & 1.63 & 0.36 & 2.86 & 1.66 & 0.47 & 2.81 & 0.99 & 0.31 & 1.65 \\
\hline Watts Index & 5.68 & 1.44 & 9.79 & 5.94 & 1.86 & 9.90 & 3.85 & 1.37 & 6.24 \\
\hline \multicolumn{10}{|l|}{$\begin{array}{l}\$ 2 / \text { day Poverty Line } \\
\text { Headcount }\end{array}$} \\
\hline poverty rate & 40.52 & 21.68 & 58.78 & 43.55 & 25.01 & 61.52 & 39.19 & 22.08 & 55.78 \\
\hline Poverty gap & 14.24 & 6.04 & 22.19 & 15.12 & 7.00 & 22.99 & 12.53 & 6.03 & 18.83 \\
\hline Severity of poverty & 6.51 & 2.35 & 10.54 & 6.86 & 2.74 & 10.85 & 5.26 & 2.28 & 8.15 \\
\hline Watts Index & 19.62 & 7.81 & 31.05 & 20.72 & 9.10 & 31.99 & 16.64 & 7.72 & 25.28 \\
\hline \multicolumn{10}{|l|}{$\begin{array}{l}0.5^{*} \text { Median Poverty } \\
\text { Line }\end{array}$} \\
\hline $\begin{array}{l}\text { Headcount } \\
\text { poverty rate }\end{array}$ & 15.39 & 4.69 & 25.76 & 15.65 & 5.75 & 25.25 & 13.00 & 5.32 & 20.45 \\
\hline Poverty gap & 3.73 & 0.93 & 6.44 & 3.51 & 1.05 & 5.90 & 2.66 & 0.95 & 4.31 \\
\hline Severity of poverty & 1.33 & 0.28 & 2.34 & 1.16 & 0.30 & 1.99 & 0.82 & 0.25 & 1.37 \\
\hline Watts Index & 4.70 & 1.12 & 8.17 & 4.33 & 1.26 & 7.31 & 3.22 & 1.11 & 5.27 \\
\hline \multicolumn{10}{|l|}{ Official Poverty } \\
\hline $\begin{array}{l}\text { Headcount } \\
\text { poverty rate }\end{array}$ & 27.00 & 12.42 & 41.13 & 28.19 & 14.01 & 41.93 & 28.41 & 15.16 & 41.25 \\
\hline Poverty gap & 7.15 & 2.75 & 11.42 & 7.44 & 3.12 & 11.63 & 7.24 & 3.53 & 10.83 \\
\hline Severity of poverty & 2.71 & 0.89 & 4.47 & 2.78 & 1.03 & 4.47 & 2.59 & 1.16 & 3.98 \\
\hline Watts Index & 9.21 & 3.38 & 14.85 & 9.51 & 3.86 & 14.99 & 9.14 & 4.34 & 13.79 \\
\hline
\end{tabular}

PHI = Philippines .

Source: Author's computations using longitudinal subsample of FIES.

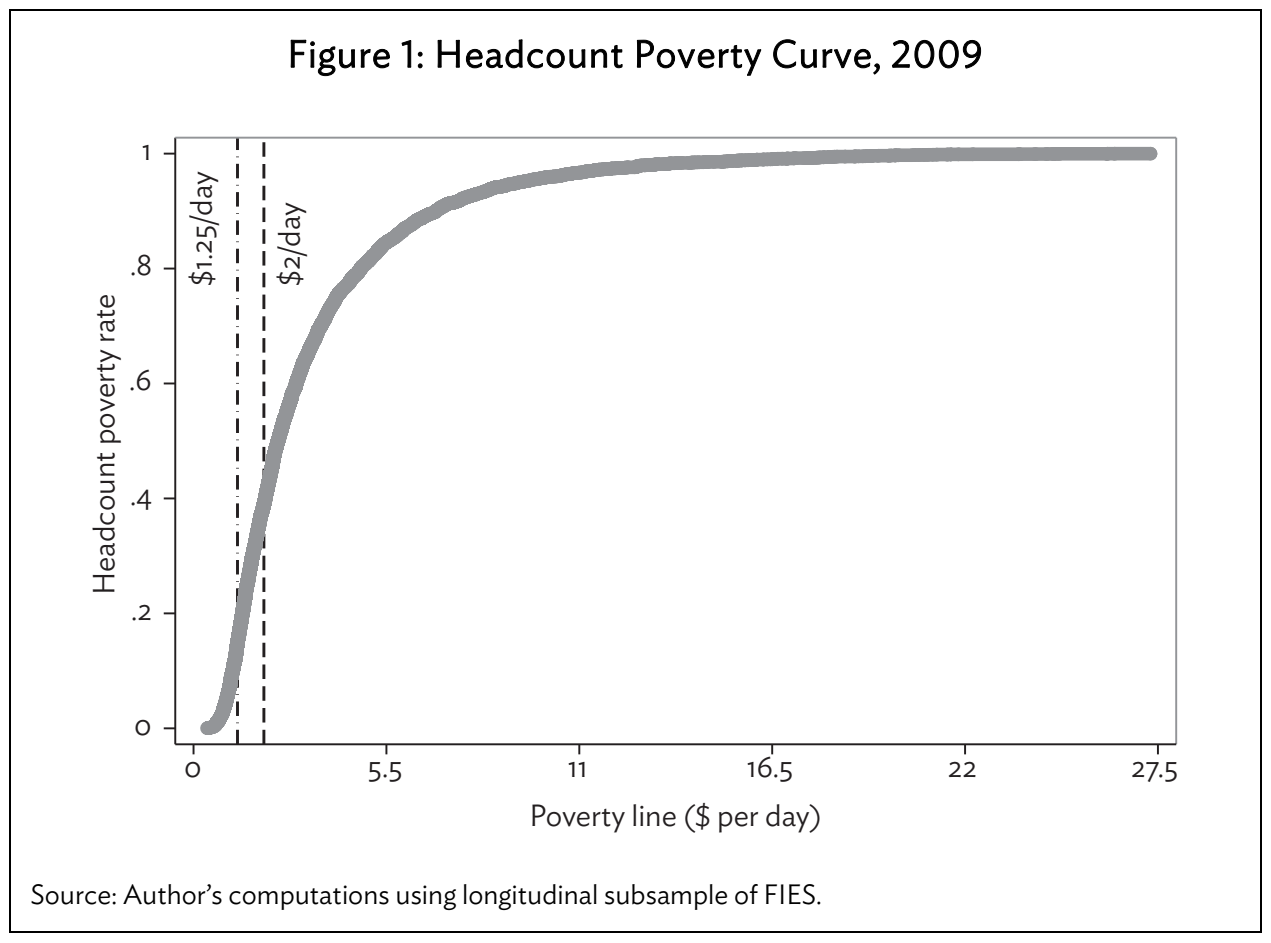




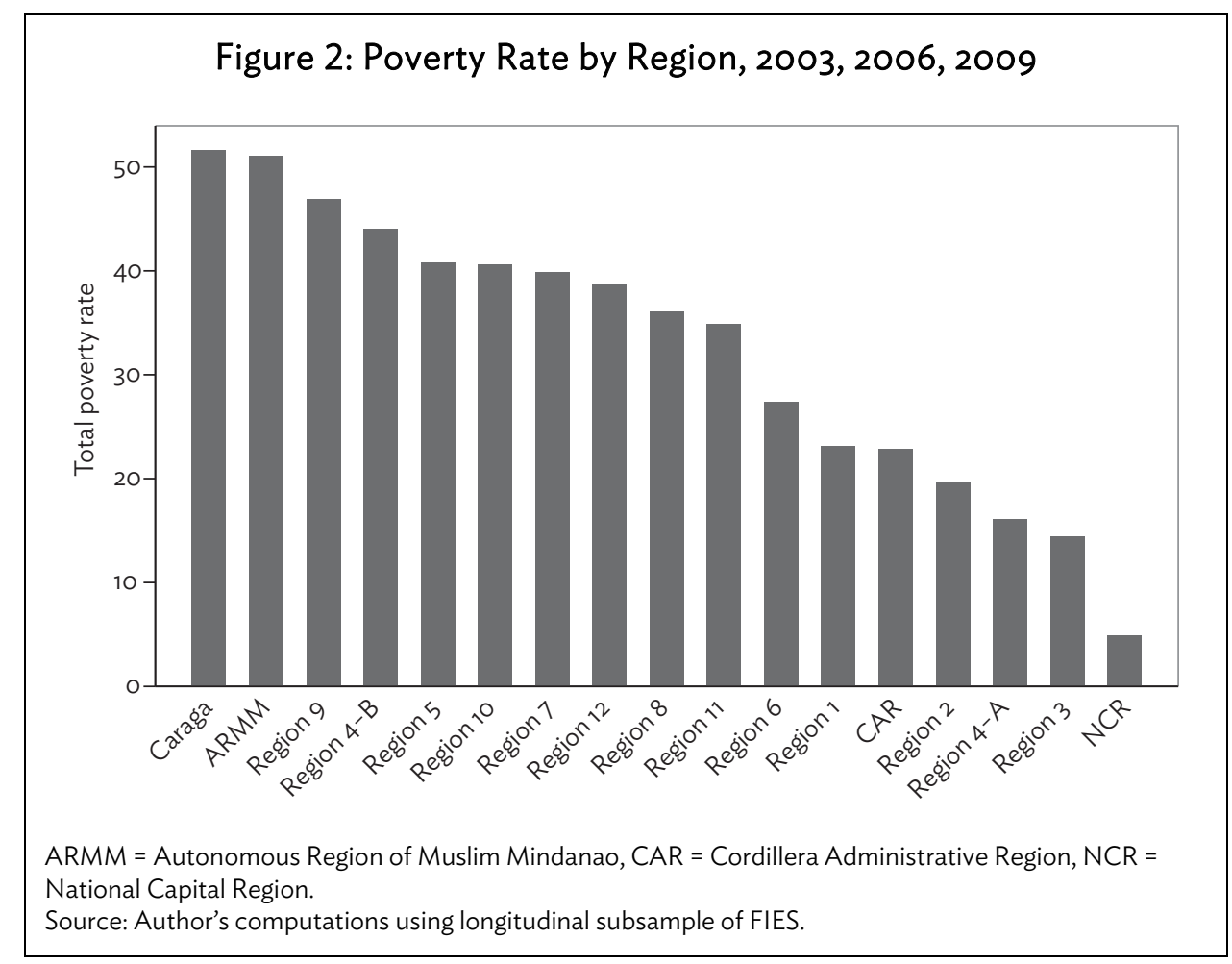

\section{Poverty Estimates Using the Components Approach}

Figures 3 and 4 show the results based on the JR and DAG approaches. For both figures, the rows correspond to the four sets of poverty lines used in the computations, while the columns correspond to the different measures of poverty estimated at the national, urban, and rural levels. The height of the bars corresponds to the magnitude of poverty wherein the dark-shaded bars correspond to persistent poverty, while the light-shaded bars correspond to transient poverty.

There are several interesting features that can be drawn from the intertemporal poverty estimates based on the JR procedure. First, most of the indicators show that poverty is mostly persistent in nature. For instance, about $96 \%$ of the total observed $\$ 2 /$ day poverty is persistent and only $4 \%$ can be attributed to the effect of transitory income short fall. Interestingly, the relative importance of persistent poverty declines with the poverty line. For example, if $\$ 1.25 /$ day poverty line is used instead of $\$ 2 /$ day, the relative importance of headcount poverty persistence drops to $87 \%$. The share of transient poverty also increases when we shift from poverty incidence to poverty gap and poverty severity. In particular, about $10 \%$ to $29 \%$ of the poverty gap and $16 \%$ to $38 \%$ of the poverty severity can be linked with transient poverty. Second, transient poverty is more common in urban areas than in rural areas. In urban areas, transient poverty accounts for approximately $11 \%$ to $29 \%$ of its total headcount poverty rate, while only $2 \%$ to $10 \%$ of the rural poverty can be attributed to transitory downturn in monetary fortunes. 


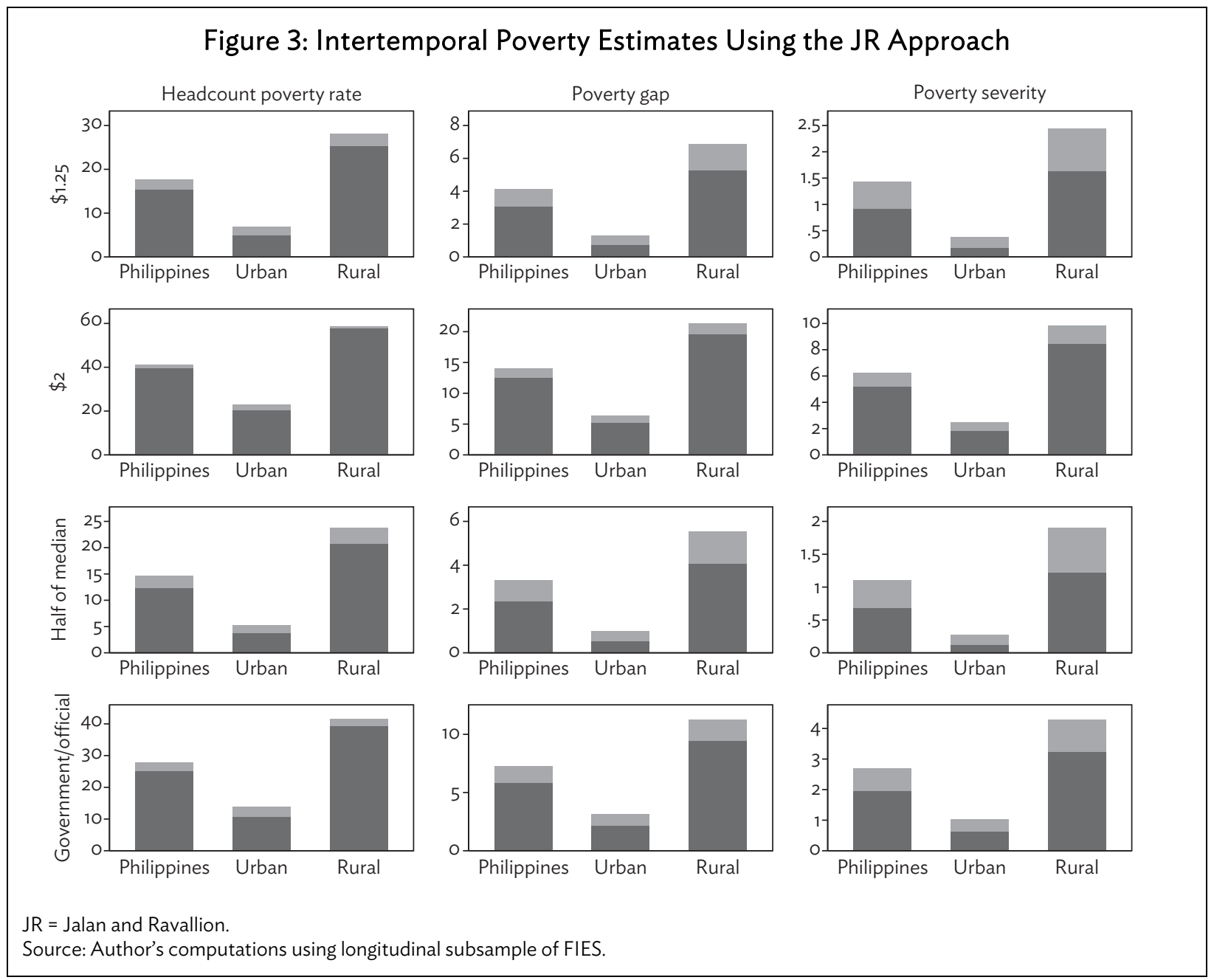

Since the JR approach does not differentiate a household with a relatively stable income flow from a household with highly fluctuating income as long as their longitudinally average incomes are equal, an interesting question to be asked is how will these poverty estimates be affected when I take into account people's risk aversion to unstable income flows? The DAG approach is used to investigate this issue. In the following analysis, I set the aversion parameter $\alpha=1.5,2$ or 2.5 . These values imply that households are not risk neutral. ${ }^{8}$ The rows in Figure 4 correspond to the different poverty lines, while the columns represent the intertemporal poverty estimates for different levels of risk aversion to income fluctuations at the national, urban, and rural level. Again the height of the dark-shaded and light-shaded bars correspond to the magnitude of persistent and transient poverty, respectively. At $\alpha=$ 1.5 and using $\$ 2$ /day poverty line, the height of the light-shaded bar suggests that households would be willing to increase the average poverty gap by 1 percentage point just to remove the variability in the income short fall observed from 2003 to 2009. If I divide the height of the light-shaded bar by the total height of the stacked bar, I find that the estimated share of transient poverty based on the DAG approach is roughly $5 \%$ to $7 \%$ of the total poverty when $\alpha=1.5$ and increases to $8 \%$ to $9 \%$ when $\alpha=2.5$. In other words, as households become more risk averse, transient poverty becomes more common.

8 A value of 1 for the risk aversion parameter $\alpha$ would imply that all households are risk neutral. Higher values imply higher level of risk aversion. 


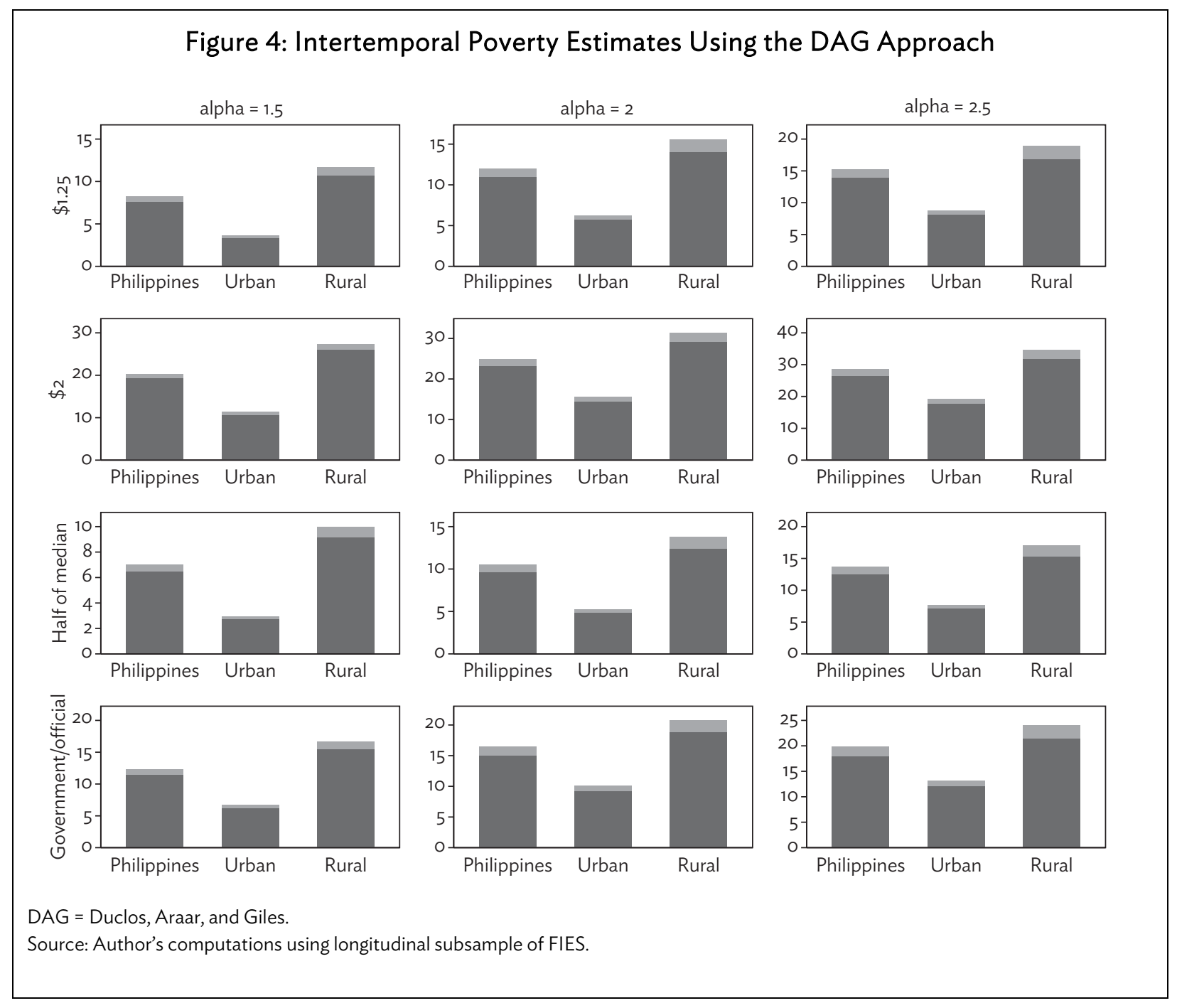

\section{Poverty Estimates using the Spells Approach}

Table 3 presents all possible poverty spells in years 2003, 2006, and 2009 with respect to different poverty lines. The results show that about $46 \%$ to $76 \%$ of the population never experienced poverty, $12 \%$ to $15 \%$ were poor for only 1 (survey) year, $9 \%$ to $13 \%$ were poor for 2 years, and $6 \%$ to $28 \%$ were consistently poor for all 3 years. Following the conventional spells approach, these numbers may also be used to estimate persistent and transient poverty. If I define poverty persistence as those who are poor for at least 2 survey years, the estimates presented in Table 3 suggest that between 16\% to 41\% of the population were persistently poor. Despite the differences in the methodologies, it is interesting to note that the spells-based estimates of poverty persistence are roughly the same as the estimated proportion of population who were persistently poor based on the JR approach. Both methodologies suggest that poverty is not just once-in-a-lifetime experience wherein a significant fraction of the population experience poverty for a long time period. However, a different story emerges when I compare the estimates of total poverty. Following the spells approach, total poverty would correspond to those who were poor for at least one time period. Given this definition, total poverty is estimated to be approximately $29 \%$ to $54 \%$ of the population. These numbers are significantly higher relative to the estimates of total poverty based on the components approach, which placed poverty at around 18\% to 
41\%. Consequently, the relative importance of persistent and transient poverty also differ across these two estimation approaches. In particular, the results based on the conventional spells approach suggest that approximately $58 \%$ to $77 \%$ of the total (headcount) poverty observed is persistent, whereas the components approach suggests that persistent poverty account for $84 \%$ to $96 \%$ of total (headcount) poverty. ${ }^{9}$

Table 3: Population Share by Intertemporal Poverty Status

(\%)

\begin{tabular}{|c|c|c|c|c|c|c|}
\hline \multirow{2}{*}{$\begin{array}{l}\text { Poverty Status } \\
(2003,2006,2009)\end{array}$} & \multicolumn{3}{|c|}{$\$ 1.25$ Poverty Line } & \multicolumn{3}{|c|}{$\$ 2$ Poverty Line } \\
\hline & $\mathrm{PHI}$ & Urban & Rural & $\mathrm{PHI}$ & Urban & Rural \\
\hline$P, P, P$ & 7.75 & 1.91 & 13.4 & 28.33 & 12.33 & 43.84 \\
\hline$P, P, N P$ & 4.55 & 1.67 & 7.33 & 5.97 & 4.10 & 7.78 \\
\hline$P, N P, P$ & 1.29 & 0.42 & 2.14 & 2.18 & 1.56 & 2.78 \\
\hline$P, N P, N P$ & 4.70 & 2.53 & 6.81 & 4.05 & 3.70 & 4.39 \\
\hline$N P, P, P$ & 2.97 & 1.57 & 4.33 & 4.83 & 4.32 & 5.32 \\
\hline$N P, P, N P$ & 3.98 & 2.17 & 5.74 & 4.42 & 4.26 & 4.58 \\
\hline$N P, N P, P$ & 3.38 & 2.64 & 4.11 & 3.86 & 3.87 & 3.84 \\
\hline$N P, N P, N P$ & 71.37 & 87.08 & 56.15 & 46.37 & 65.86 & 27.47 \\
\hline \multirow{2}{*}{$\begin{array}{l}\text { Poverty Status } \\
(2003,2006,2009)\end{array}$} & \multicolumn{3}{|c|}{ Half of Median Poverty Line } & \multicolumn{3}{|c|}{ Govt Poverty Line } \\
\hline & $\mathrm{PHI}$ & Urban & Rural & $\mathrm{PHI}$ & Urban & Rural \\
\hline$P, P, P$ & 5.91 & 1.33 & 10.34 & 15.50 & 6.12 & 26.36 \\
\hline$P, P, N P$ & 3.58 & 1.07 & 6.00 & 4.05 & 1.93 & 6.24 \\
\hline$P, N P, P$ & 1.39 & 0.33 & 2.42 & 2.72 & 1.32 & 4.16 \\
\hline$P, N P, N P$ & 4.52 & 1.95 & 7.00 & 5.20 & 3.68 & 6.83 \\
\hline$N P, P, P$ & 2.80 & 1.67 & 3.88 & 5.02 & 3.48 & 6.68 \\
\hline$N P, P, N P$ & 3.38 & 1.67 & 5.03 & 4.13 & 3.19 & 5.17 \\
\hline$N P, N P, P$ & 2.91 & 1.99 & 3.81 & 5.69 & 5.00 & 6.52 \\
\hline NP,NP,NP & 75.53 & 89.98 & 61.52 & 61.08 & 80.29 & 44.03 \\
\hline
\end{tabular}

$\mathrm{NP}=$ Nonpoor, $\mathrm{P}=$ Poor, $\mathrm{PHI}=$ Philippines

Source: Author's computations using longitudinal subsample of FIES.

As pointed out at the beginning of this study, the concepts of persistent and transient should not be used interchangeably because they are measuring different aspects of socioeconomic disadvantage. Measuring persistent and transient poverty at the national-level is the first step to understand the dynamic feature of poverty in the country. Overall, the results presented in this section suggest that poverty in the Philippines can be considered to be mostly persistent in nature. Nevertheless, the magnitude of transient poverty is not negligible. The findings of the robustness checks show that the share of transient to total observed poverty tends to increase dramatically as we increase the poverty line and/or use a poverty index that is more sensitive to the illfare of the poorest of the poor.

9 Had I defined persistent poverty as those who experienced poverty for 2 consecutive survey years, the relative importance of persistent poverty is approximately $50 \%$ to $73 \%$. 


\section{B. Where are the Persistently and Transiently Poor?}

In this section, I extend the previous discussions by estimating intertemporal poverty at the subnational level. In general, locating where the poor are is important for socioeconomic planning. For one, it makes the delivery of social services more efficient and cost-effective (Kanbur 1987). It also helps exploit dynamic externalities and geographic spillover effects of economic growth and pointing toward more efficient and complementary poverty reduction programs (Ravallion and Jalan 1996). However, previous studies that examined the spatial distribution of poverty in the Philippines do not clarify whether the areas with the highest levels of total poverty are also the same location as those areas with the highest levels of persistent or transient poverty. This is important to know because policy makers may be more concerned on channeling resources to areas with slightly lower levels of total poverty but with more prevalent persistent poverty than areas with higher levels of total poverty but significantly lower poverty persistence. Furthermore as pointed out earlier, persistent and transient poverty call for different policy mix.

This section revisits the spatial distribution of intertemporal poverty in the Philippines. Similar to the previous section, estimates are presented for both the components and spells approaches. This allows us to evaluate the robustness of spatial poverty rankings across the methodologies considered in this study. Although this section does not provide more disaggregated estimates beyond the regional-level due to sample size restrictions, the analysis identifies proximate areas that could be potentially useful for the targeting of poverty-reduction programs. ${ }^{10}$

\section{Components Approach}

Figure 5 shows the intertemporal poverty estimates for the 17 geographic regions in the Philippines using the components approach proposed by Jalan and Ravallion (1998). The columns represent the estimated incidence, depth, and severity of poverty, while the rows correspond to the different poverty lines used. One take on the results is that, when longitudinal average income data is used, it provides evidence that is consistent with an orthodox view that most of the persistently poor live in the regions with the lowest average per capita income. In particular, I find that Regions 4B, 9, Caraga and ARMM have the highest prevalence of total poverty and poverty persistence. Not surprisingly, these regions have the lowest per capita longitudinally averaged income. On the other hand, the National Capital Region (NCR), the region with the highest average permanent income, posted the lowest total poverty and poverty persistence rate. Other regions with low poverty persistence are also from the northern Philippines which include Regions 3 and 4A.

Focusing on the robustness of the results, we find that the regional ranking of poverty persistence is relatively uniform across varying parameters used in the estimation process. Nevertheless, there are slight changes in the rankings that are worth pointing out when estimation parameters are changed. For example, the magnitude of persistent poverty tends to be higher in Region 9 when lower poverty lines or poverty measures that are more sensitive to the welfare of the poorest of the poor are used. The opposite happens for Caraga wherein poverty persistence decreases when either lower poverty lines or more inequality-sensitive measures are used.

10 A more informative exercise is to provide estimates at the administrative level (e.g., provinces or municipalities). However, the small sample sizes may lead to high standard errors of intertemporal poverty estimates. In this context, there are several small area estimation techniques that can be used (Martinez [2012]; Elbers, Lanjouw, and Lanjouw [2003], etc.). 
A high level of transient poverty is indicative of how erratic a household income flow is over time. Understanding how erratic income flows create poverty cycles in certain areas is important to be able to prevent economic stagnation. Thus, like persistent poverty, it is also instructive to examine the regional distribution of transient poverty. Interestingly, a separate examination of transient poverty reveals a very different picture compared to what the estimates of poverty persistence portray. Figure 6 shows that it is not necessarily the case that regions with the highest persistent poverty are also the regions with the highest transient poverty. Furthermore, in contrast to poverty persistence wherein the regional ranking is quite robust under various scenarios, the regional ranking with respect to transient poverty heavily depends on the poverty line and type of poverty measure used. For example, the NCR ranks third among the regions with the highest proportion of households that are transiently poor with respect to the $\$ 2$ poverty line but it ranks last with respect to other measures of poverty persistence. On the other hand, ARMM posted the lowest transient poverty with respect to $\$ 2$ poverty threshold."

When aversion to income fluctuations is taken into account by using the DAG approach, the regions with high and low persistent and transient poverty can be identified (Figure 6).

$1 \quad$ As pointed out earlier, the JR approach does not ensure that the total poverty is always greater than or equal to poverty persistence. This happens in the case of Region 7 and ARMM wherein the computed $\$ 2$ transient poverty rates are negative. 


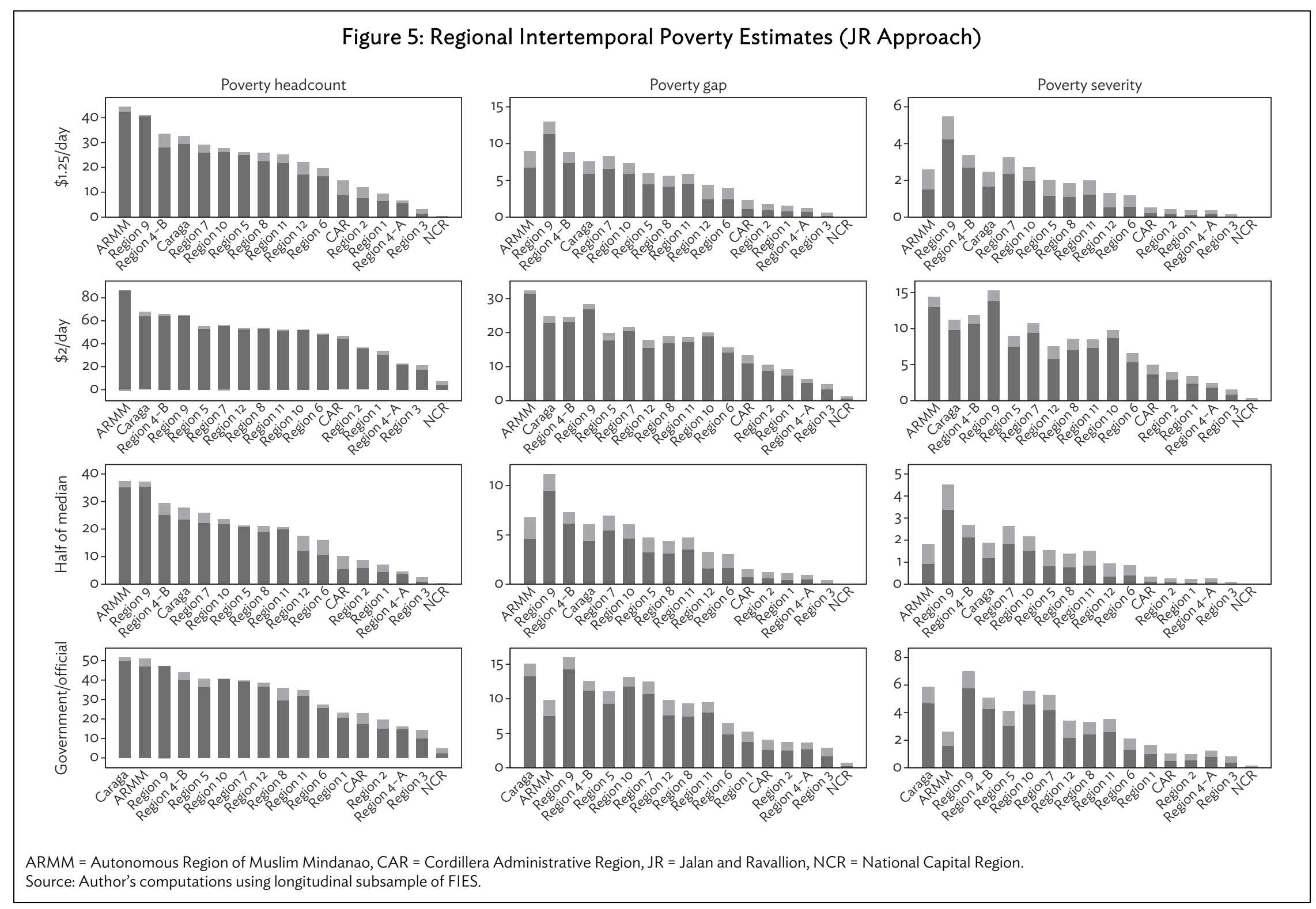




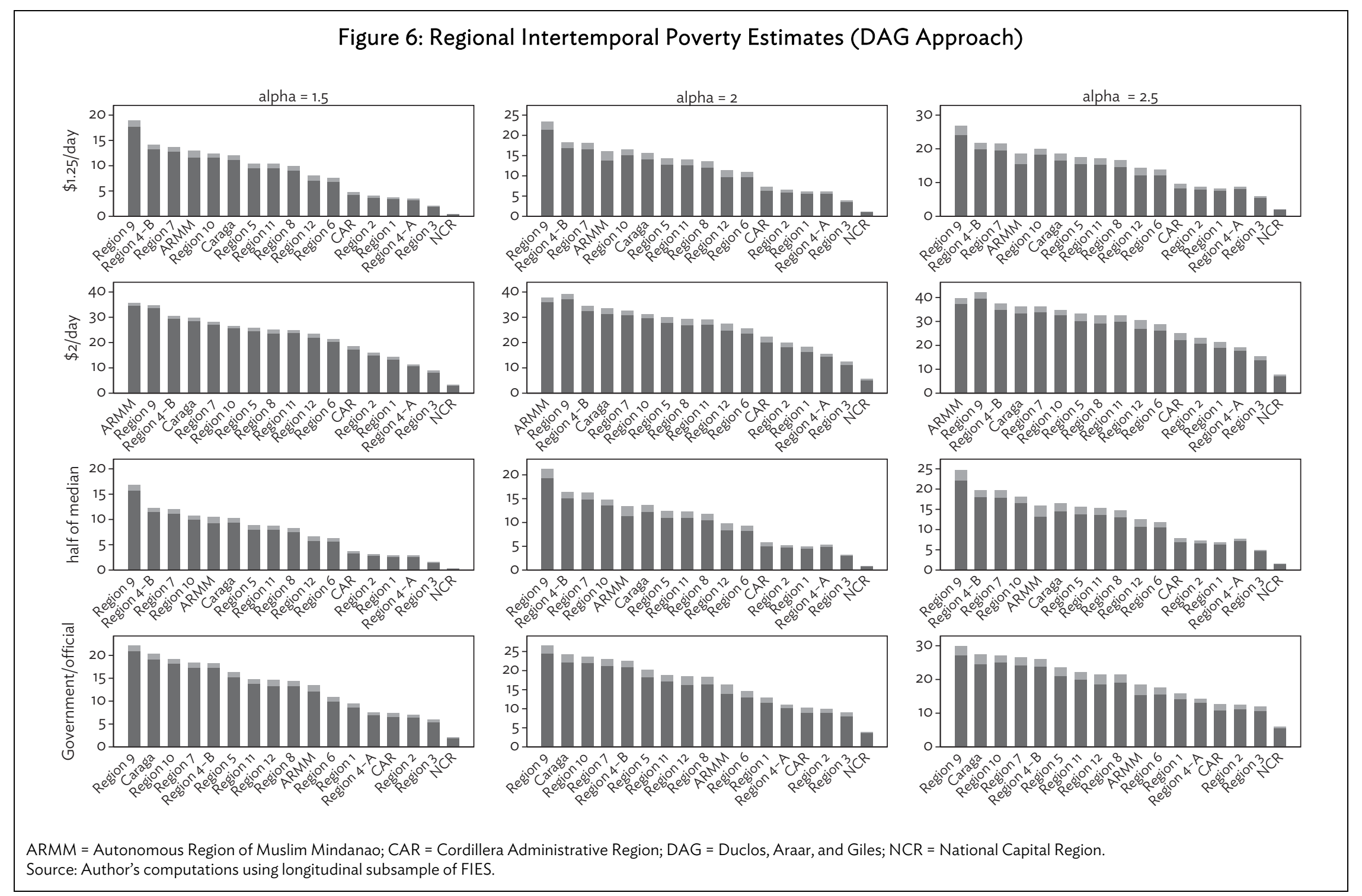




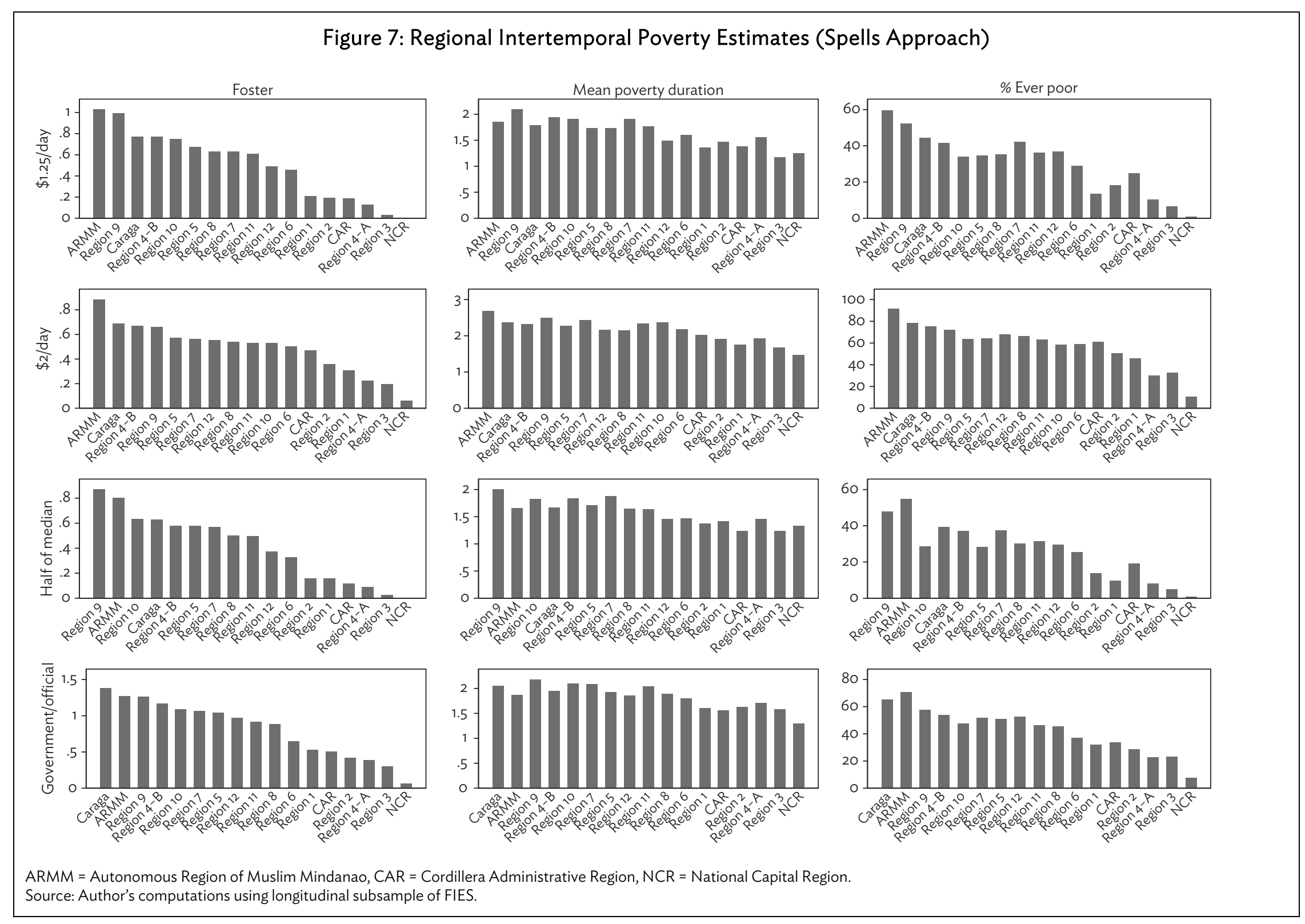




\section{Spells Approach}

Figure 7 shows the estimates of selected indicators of intertemporal poverty following the spells approach. In particular, the first column presents the duration-adjusted poverty headcount ratio proposed by Foster (2009), while the second and third columns present selected indices from the class of intertemporal poverty measures proposed by Gradin and del Rio (2012). It is clear from Figure 7 that Regions 7, 9, ARMM and Caraga have the highest intertemporal poverty estimates. In 7 out of 12 indicators, ARMM ranked first among the regions with the highest levels of poverty. For instance, roughly 55\% to $90 \%$ of the household population in ARMM have experienced poverty for at least one episode from 2003 to 2009. Interestingly, except for the \$2/day poverty line, ARMM is not in the list of four regions with the highest average duration of poverty. Nevertheless, the average duration of poverty is still relatively high because a typical poor household in ARMM experienced poverty in 2 out of the 3 survey years. Like ARMM, Region 9 has widespread poverty that persists over the years. In fact, the estimates show that Region 9 posted the highest average poverty duration wherein households spend 2.1 to 2.5 (survey) years living with income less than the poverty line. In contrast, Regions 3, 4A, and the NCR have consistently shown the lowest intertemporal poverty levels.

In summary, poverty in the Philippines has a remarkable spatial feature. In general, most of the regions with the highest levels of chronic or persistent poverty are in the southern part of the Philippines: Regions 7, 9, ARMM, and Caraga. This is in sharp contrast with the regions that posted the lowest levels of poverty persistence which are all located up north, close to the country's center of commerce. At the same time, if I investigate the economic structure of each region, I would find that the areas which rely heavily in the agriculture sector tend to have higher proportion of persistently poor households. This is consistent with the findings from a number of studies that have concluded poverty in the Philippines a predominantly rural and agricultural phenomenon (ADB 2005, 2009). There are several substantial explanations for this. First, agricultural growth is hard to sustain because of extreme and unpredictable weather. The Philippines sits in one of the most tropical cyclone-prone areas in the world and every year, the country experiences an average of 10 typhoons (PAG-ASA 2013). ${ }^{12}$ These weather disturbances often have debilitating effects as estimates suggest that a strong typhoon in the Philippines can destroy more than $\$ 75$ million (approximately P3 billion using prevailing exchange rates) worth of agricultural crops (PAG-ASA 2013). Small-scale agricultural workers are usually the most affected because their produce over several months can be wiped out easily by one typhoon. Not surprisingly, weak property rights in the Philippines also contributes to why rural households are trapped in longer poverty episodes compared to their urban counterparts. Despite the agrarian reforms that have been implemented in the Philippines since the 1970s which aim to improve the welfare of the low-income households in rural areas who depend on access to land for their day-to-day living, existing institutions (e.g., credit markets) have not delivered the economic opportunities envisaged by the reform (Balisacan 2002). Inadequate provision of socioeconomic services (e.g., lack of access to concrete or paved roads) also exacerbates the chronic poverty in these regions (ADB 2005, 2009).

Although more urbanized regions like Regions 3, 4A, and the NCR show lower levels of persistent poverty, transient poverty is not a trivial problem in these areas. What are the causes of transient income downturn in urban areas? One is the lack of opportunities due to population strain. As the prospects of more economic opportunities usually attract the rural poor to migrate to urban centers, urban population starts growing rapidly. The scarce opportunities available for the growing population can lead to a highly unstable income flow. Second, it is also widely perceived that people living in urban areas are more exposed to health and safety risks due to makeshift housing, poor

12 PAG-ASA is the Philippines' weather bureau. 
sanitation, fire hazards, and crime (Housing and Urban Development Coordinating Council 2008, ADB 2009). In general, when socioeconomic shocks erode the meagre assets accumulated by households, they can be pulled back into transient poverty.

Although the different intertemporal poverty estimation tools have produced roughly similar lists of regions with the highest and lowest levels of poverty persistence, the rankings are not perfectly robust across all approaches, especially with respect to transient poverty. While it may be true that the minimal differences in the regional rankings may not have a profound policy impact, the impact may be more severe if a similar computational exercise was undertaken at finer administrative levels where resources are allocated on the basis of various indicators which includes poverty. ${ }^{3}$ However, due to sample size limitations, this study did not conduct a rigorous intertemporal poverty ranking of the provinces. This is reserved for future research.

\section{Who are the Persistently and Transiently Poor?}

The objective of this section is to draw our attention to the possible heterogeneity in the intertemporal poverty experience of Filipino households. Table 4 summarizes the results of the statistical models that I estimated to measure the impact of each correlate in the presence of other household characteristics using the components and spells approach and different poverty line specifications. In particular, it shows the regression coefficients of the multinomial logistic models for the probability of being classified as persistently poor, transiently poor, and nonpoor. These coefficients can be interpreted as multinomial log-odds, i.e., for a unit change in the explanatory variable, the logit of the propensity to be classified as persistently poor (or transiently poor) relative to being nonpoor will change by an amount equivalent to the regression coefficient, holding all other explanatory variables constant. ${ }^{14}$

In general, the models confirm the importance of standard sociodemographic characteristics like sex, age, and education in explaining a household's intertemporal poverty status. In particular, the results show that female-headed households are at risk of spending more time in poverty than maleheaded households. Female-headed households in many developing countries are usually characterized as a vulnerable group due to the presumed lack of ability of women to mobilize socioeconomic resources for the family. On the other hand, the age of the household head presents a typical concave relationship with income and consequently, a convex relationship with the length of stay in poverty. In particular, during prime age years, individuals are in the process of climbing up the occupational ladder. With higher income accompanying this process, these people have less risk of falling into poverty. However, beyond a certain age threshold, individuals start to experience income deterioration. For instance, some of those who used to work in the formal sector could only rely mostly on pensions after retirement, representing a fraction of their previous income. With advancement in age, some of those who work in the informal sector have less employment opportunities because they are less capable of performing physical tasks that jobs in the informal sector entail. Furthermore, the estimated models reiterate the importance of education in minimizing the risk of falling into poverty. In particular, I find that better educated individuals as proxied by the educational attainment of the head

13 There are several examples of poverty reduction programs in the Philippines that rely on the reliability of poverty rankings. For example, only households living in selected municipalities from the 20 poorest provinces are eligible for the national government's conditional cash transfer program during the first stages of its inception (Reyes and Tabuga 2012). Other government agencies such as PhilHealth, a government-owned corporation that provides health insurance, as well as nongovernment agencies also use poverty rankings to identify areas that need priority assistance (Addawe, Martinez, and Perez 2007).

14 If I take the exponential of these regression coefficients, I will get the relative risk ratios. 
of the household, face less risk of long poverty spells. In this context, higher educational attainment serves as a mechanism for expanding one's overall social mobility prospects. This is consistent with the human capital theory which suggests that the skills and knowledge imparted by higher educational attainment improves an individual's productivity, and in turn, his/her ability to mobilize resources (Tilak 2002). While educational attainment explains a significant portion of the differences in household income and poverty status, education remains to be a development puzzle in the country. For instance, compared to other countries with similar level of development, the Philippines has much higher gross enrollment rates in secondary and tertiary education (WDI 2013). Despite this advantage, significant pockets of poverty remain in the country. In fact, other Southeast Asian countries such as Indonesia and Thailand with almost the same levels of secondary and tertiary enrollment rates have significantly better poverty trends. This finding is consistent with the notion that the quality of education in the Philippines has to be improved. However, this may also be linked to the deficient demand for nonagricultural labor (Felipe and Lanzona 2006). In general, it is imperative for socioeconomic planners to implement policies that will make the education system more responsive to the needs of the poor. ${ }^{15}$

Table 4: Regression Coefficients of Multinomial Logistic Models for Intertemporal Poverty in the Philippines Using Three Waves of Panel Data: 2003, 2006, and 2009

$$
\text { (Base }=\text { Nonpoor) }
$$

\begin{tabular}{|c|c|c|c|c|c|c|c|c|}
\hline & \multicolumn{4}{|c|}{ Components Approach } & \multicolumn{4}{|c|}{ Spells Approach } \\
\hline & \multicolumn{2}{|c|}{$\$ 1.25$} & \multicolumn{2}{|c|}{$\$ 2$} & \multicolumn{2}{|c|}{$\$ 1.25$} & \multicolumn{2}{|c|}{$\$ 2$} \\
\hline & Persistent & Transient & Persistent & Transient & Persistent & Transient & Persistent & Transient \\
\hline Main island (base $=\mathrm{NCR}$ ) & & & & & & & & \\
\hline Luzon & 14.74 & $1.615^{* *}$ & $1.761^{* * *}$ & $.7193^{* *}$ & 1.738 & $1.835^{* *}$ & $1.37^{* * *}$ & $.7893^{* * *}$ \\
\hline Visayas & 15.94 & $2.246^{* * *}$ & $2.63^{* * *}$ & $.8773^{* * *}$ & $2.871^{* *}$ & $2.439^{* * *}$ & $2.161^{* * *}$ & $.918^{* * *}$ \\
\hline Mindanao & 16.18 & $2.438^{* * *}$ & $3.055^{* * *}$ & $1.192^{* * *}$ & $3.093^{* *}$ & $2.643^{* * *}$ & $2.645^{* * *}$ & $1.15^{* * *}$ \\
\hline 1 if urban & $-.7792^{* * *}$ & $-.3362^{* *}$ & $-.8372^{* * *}$ & $-.4097^{* * *}$ & $-.6535^{* * *}$ & $-.3525^{* *}$ & $-.752^{* * *}$ & $-.4219^{* * *}$ \\
\hline 1 if household head is male & $-.8212^{*}$ & -0.02772 & -0.3164 & 0.1372 & $-.7392^{*}$ & 0.01908 & -0.3364 & 0.2069 \\
\hline Household head's age & $-.146^{* * *}$ & $-.07295^{* * *}$ & $-.06805^{* *}$ & $1.29 \mathrm{E}-02$ & $-.146^{* * *}$ & $-.0658^{* *}$ & $-.04758^{*}$ & 0.008981 \\
\hline Household head's age ${ }^{2}$ & $.001539^{* * *}$ & $.0007989^{* * *}$ & $.0008414^{* * *}$ & $1 \mathrm{E}-05$ & $.001547^{* * *}$ & $.000721^{* * *}$ & $.0006263^{* *}$ & 0.00005388 \\
\hline $\begin{array}{l}\text { Marital status of household } \\
\text { head }(\text { base }=\text { Single })\end{array}$ & & & & & & & & \\
\hline $\begin{array}{l}1 \text { if household head is } \\
\text { married }\end{array}$ & -0.1719 & $-.7561^{*}$ & 0.1995 & 0.0541 & -0.06679 & $-.854^{* *}$ & 0.2322 & -0.004984 \\
\hline $\begin{array}{l}1 \text { if household head is } \\
\text { widowed/separated/ }\end{array}$ & & & & & & & & \\
\hline others & -0.9965 & $-.8357^{* *}$ & -0.5165 & -0.03779 & -0.8185 & $-.8883^{* *}$ & -0.4676 & -0.02353 \\
\hline $\begin{array}{l}\text { Educational attainment of } \\
\text { household head (base = } \\
\text { Primary education) }\end{array}$ & & & & & & & & \\
\hline 1 if secondary education & $-1.168^{* * *}$ & $-.6984^{* * *}$ & $-1.059^{* * *}$ & $-.3709^{* * *}$ & $-.9229^{* * *}$ & $-.7924^{* * *}$ & $-1.007^{* * *}$ & $-.314^{* *}$ \\
\hline 1 if college education & $-2.815^{* *}$ & $-1.69^{* * *}$ & $-2.782^{* * *}$ & $-1.255^{* * *}$ & $-2.813^{* *}$ & $-1.723^{* * *}$ & $-2.717^{* * *}$ & $-1.117^{* * *}$ \\
\hline Household type: & 0.07459 & 0.115 & -0.1549 & 0.1655 & -0.07087 & 0.1817 & -0.1142 & 0.163 \\
\hline Household type: & -11.13 & -16.69 & -13.45 & 0.7791 & -9.873 & -12.28 & -12.91 & 0.8591 \\
\hline Proportion of household & & & & & & & & \\
\hline members who are young & $3.247^{* * *}$ & $1.297^{* * *}$ & $3.364^{* * *}$ & $1.538^{* * *}$ & $2.72^{* * *}$ & $1.381^{* * *}$ & $3.119^{* * *}$ & $1.487^{* * *}$ \\
\hline Family size & $.742^{* * *}$ & $.4392^{* * *}$ & $.8163^{* * *}$ & $.3285^{* * *}$ & $.7093^{* * *}$ & $.428^{* * *}$ & $.7315^{* * *}$ & $.3336^{* * *}$ \\
\hline 1 if agricultural household & $.8974^{* * *}$ & $.2856^{*}$ & $1.176^{* * *}$ & $.4413^{* *}$ & $.8569^{* * *}$ & $.2588^{*}$ & $1.073^{* * *}$ & $.4618^{* *}$ \\
\hline
\end{tabular}

15 In 2014, the Philippines started shifting from a 10-year to 12-year basic education system. The new 12-year basic education system, commonly referred as $\mathrm{K}-12$, aims to raise the quality of education in the country and be at par with other countries in Southeast Asia. 


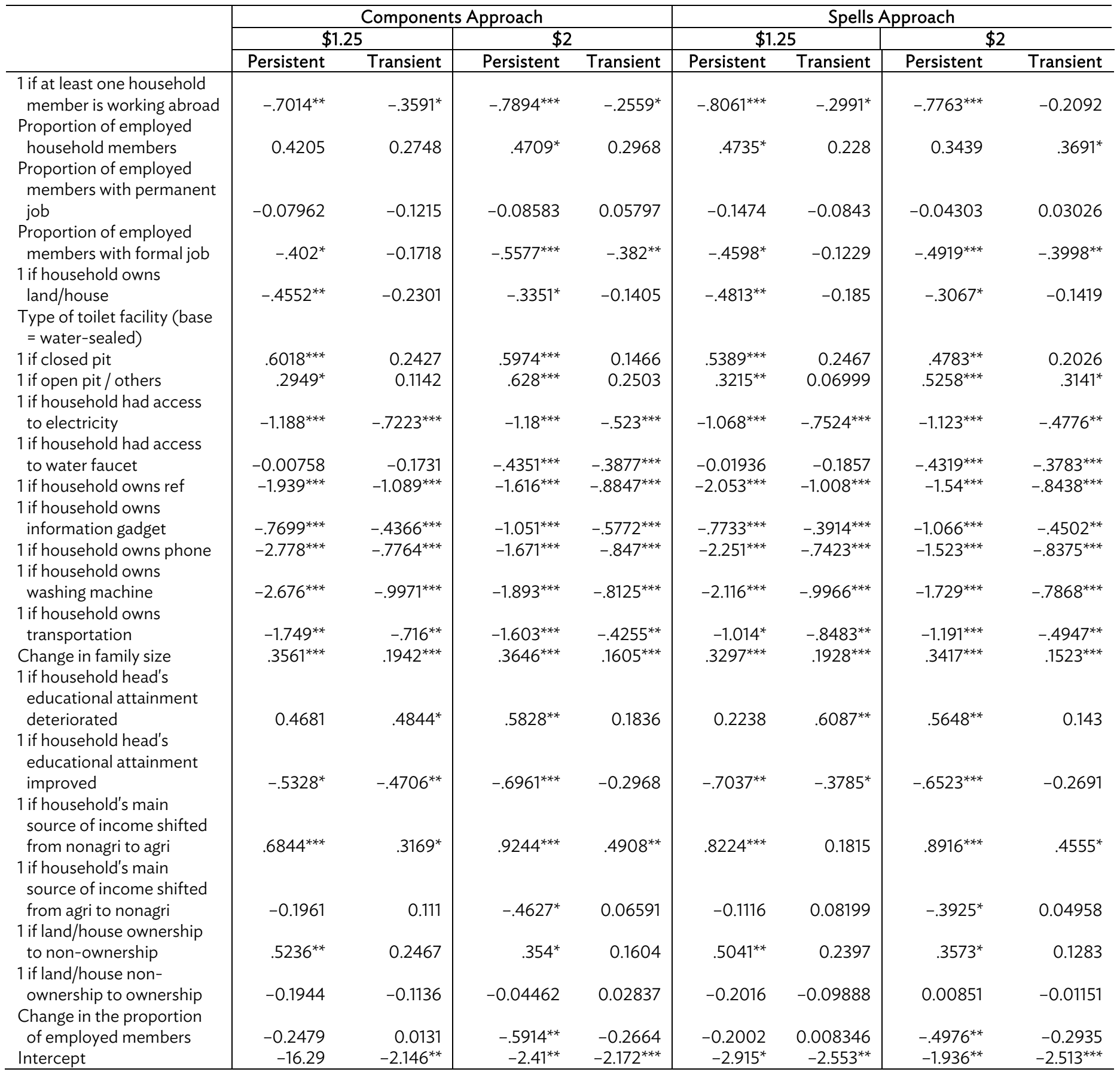

NCR = National Capital Region.

Source: Author's computations using longitudinal subsample of FIES.

Household composition is also a significant explanatory factor in inferring an individual's length of stay in poverty. The results of the estimated models suggest that individuals living in larger households have higher risks of experiencing longer poverty spells. In particular, the odds of staying in poverty increases with the number of dependent children in the family. This is consistent with the mounting evidence suggesting that lower fertility is correlated with improved socioeconomic outcomes. In particular, instead of allocating a portion of its available resources for more productive 
economic activities, households must reallocate its available resources for every additional member. For example, having more dependent children in the family limits the ability of women to engage in paid employment as they are usually expected to do child-rearing (Adair et al. 2002). At the same time, having more children in the family could also have a negative impact on household savings. For instance, using data from the 2009 FIES, I estimate that the correlation between the number of children and household saving is -0.11 ( $p$-value<0.0001). Since larger households have less savings, they are more vulnerable to unexpected income shocks arising from illness, unemployment, among other factors, that lead to reduced income flows. Nevertheless, larger household sizes could also have a negative impact on the duration of poverty spell in the later stage of the household's life cycle. For instance, the estimated models suggest that the risk of staying in poverty decreases with the proportion of household members who are working. In this context, some argue that parents who were initially disadvantaged during their early child-rearing years would fare better in the future because there will be more children to contribute in mobilizing resources for the household. However, several arguments have been offered against this hypothesis. For instance, studies show that an additional child in the household reduces the probability of other children in the family being enrolled in school (Conley 2000) which in turn, may hinder these children from reaching their full economic potential in the future. In other words, while they may be able to contribute to income generation for the household, the income may be at suboptimal levels.

The patterns of poverty dynamics in the country have a remarkable spatial feature. Overall, the results of the estimated models suggest that those who live in rural areas particularly in the southern part of the country have higher risks of staying in poverty. ${ }^{16}$ On the other hand, individuals living in urban areas where most of the economic activities are centred, experience shorter poverty spells. Some even argue that longer-than-average poverty spells in urban areas may be partly considered as a spillover effect of the socioeconomic disadvantage in rural areas (CEDAW 2009, Reyes 2002). This is because many of the poor in urban areas originally came from poor rural areas. In general, the prominent spatial feature of the distribution of poverty is not unique in the Philippines. In many developing countries, significant pockets of poverty are clustered in specific areas (Hennigner and Snel 2002, Bigman and Fofack 2000). Factors like climate, geography, natural resources, access to urban centers, and local political conditions drive the significant spatial variations in the length of poverty spells (Ravallion and Wodon 1997). The model results also confirm that access to basic services such as electricity, clean water, and sanitary toilet facilities is correlated with intertemporal poverty. For instance, having access to electricity contributes positively to higher household savings since a unit cost of lighting with electricity is generally cheaper than using candles or oil lamp. In turn, households can then use the additional savings as a cushion against the risk of falling into poverty in the future. On the other hand, experts agree that access to clean water and sanitation facilities (e.g., sanitary toilets) has a multiplier effect on many socioeconomic indicators particularly, movements into and out of poverty. In particular, access to these facilities have a direct impact on health outcomes. Not surprisingly, those who lack access to clean water and sanitation facilities have higher risks of contracting diseases like cholera, typhoid, infectious hepatitis, and polio. Consequently, these health shocks may contribute to income depletion of affected households, pushing them toward poverty. On the other hand, the cost savings incurred by households with access to electricity, clean water and sanitation facilities may contribute to a household's increased propensity to start-up incomegenerating (micro) entrepreneurial activities. The estimated models also suggest that ownership of land and other less productive (disposable) assets like television, radio, telephone, washing machine, among others is negatively correlated with the duration of poverty spells. There are several reasons why this is the case. For instance, during periods of economic uncertainties, these assets may be sold

16 Most of the poorest provinces are in Mindanao. In addition, the risk of persistent poverty is highest in Mindanao. 
to cushion the disruptions in income flows. Some of these assets may also be used to improve access to information that will enhance efficiency for planning their routine economic activities. For example, farmers who own television or radio may be warned about an impending weather disturbance earlier. More importantly, many of these assets could also be used to generate income. A popular example in the Philippines is that ownership of mobile phones can be used to start a microenterprise offering reloading prepaid credit service for mobile phone users. ${ }^{17}$

Variation in employment outcomes is one of the statistically significant factors that can explain the observed differences in the duration of poverty spells. Labor serves as one of the few assets that lowincome individuals have access to. In this context, having more household members who are working would naturally decrease the risk of staying in poverty for extended periods of time. This is confirmed by the negative coefficient of the proportion of household members who are employed, on poverty status as discussed earlier. But beyond the number of members working for the family, the type of employment also matters. For instance, the estimated models suggest that individuals living in households which rely mostly on wages, particularly in nonagriculture sectors, experience shorter poverty spells than those who rely on agricultural wage employment or earnings from self-employment. The level of productivity in the agriculture sector is one of the reasons why this is the case. In particular, low agricultural productivity is the root of persistent poverty in many developing countries. In addition to low productivity, frequent income fluctuations arising from crop loss (due to weather disturbances) or sudden changes in food prices also contribute to longer poverty durations for those who rely on agricultural wage employment. Among agricultural workers, farmers and fishermen have the highest risk of more severe poverty spells (NSCB 2012). Like agricultural wage employment, self-employment is also correlated with longer poverty durations relative to those who rely on nonagricultural wage employment. Although they do not comprise a homogeneous group, a significant bulk of the self-employed in many developing countries including the Philippines are working on own account with significantly less income. Banerjee and Duflo (2007) argue that much of the self-employed in developing countries are running their business because "they are still relatively poor and every little bit helps" until they find a more stable wage job. In the case of the Philippines, this is confirmed by the study of Hasan and Jandoc (2010) who concluded that the majority of the self-employed in the country are not "capitalists in waiting." In this context, it is not surprising to note that transitions from either agricultural wage or self-employment into nonagricultural wage employment reduces the risk of long poverty spells. Similarly, employment in the formal sector decreases the risk of being trapped in longer episodes of poverty. Compared to an informal job, a typical job in the formal sector is associated with higher and more stable income flows. Formal jobs also offer wider social protection coverage. These features serve as a cushion for unexpected income shocks which in turn, decreases the risk of falling into poverty. Interestingly, the negative effect of formal employment is stronger in the $\$ 2$ poverty line-based model suggesting that having a formal job is not quite common among the poorest of the poor. Lastly, individuals living in households where at least one member is working abroad tend to spend less time in poverty. The Philippines is one of the large labor-exporting countries and previous studies suggest that it contributes to improved macro and micro socioeconomic outcomes for the country (Ang, Sugiyarto, and Jha 2009). For instance, remittance from a migrant worker abroad eases liquidity constraint for many low-income households. This allows households to restructure their economic activities away from traditional subsistence activities and toward more efficient economic ventures (Brown and Leeves 2011). ${ }^{18}$ In addition, remittance from abroad has a

17 The idea is that mobile phone users who ran out of call or text credits but who do not have a lot of money may buy a small amount worth of credits from other mobile phone users. This type of transaction is particularly common for low-income individuals.

18 Some argue that international remittance could also lead to negative outcomes on a household's welfare. For instance, Rodriguez and Tiongson (2001) find that households with migrant workers have lower labor force participation rates and 
positive impact on investment on productive assets which in turn, could lead to lower risks of falling into poverty. Similarly, domestic remittances also contribute positively to minimizing poverty durations. In fact, its impact on the length of poverty spells could be stronger than remittance from abroad because low-income individuals are more likely to receive remittance from internal migration (Pernia 2008).

\section{VI. $\quad$ ROBUSTNESS CHECK: SWITCHING FROM 2005 TO 2011 PURCHASING POWER PARITY}

The World Bank recently updated the global poverty numbers from using 2005 PPP to using 2011 PPP. In particular, the global poverty line has been updated from $\$ 1.25$ to $\$ 1.9$. This means that the real value of $\$ 1.25$ in 2005 is the same as the value of $\$ 1.9$ in 2011. Although adopting a new PPP is not expected to have a significant change in global poverty rates, the poverty estimates for individual countries may vary significantly. This section briefly examines the implications of adopting 2011 PPP for estimating the Philippines' poverty numbers.

Figure 8 compares the headcount poverty rates estimated using 2005 and 2011 PPP. In general, the 2011 PPP-based poverty estimates are lower by approximately 5\%, except in $1994 .{ }^{19}$ In terms of poverty dynamics, I find that the proportion of people moving into and out of poverty does not change significantly after adopting the 2011 PPP (Table 5).

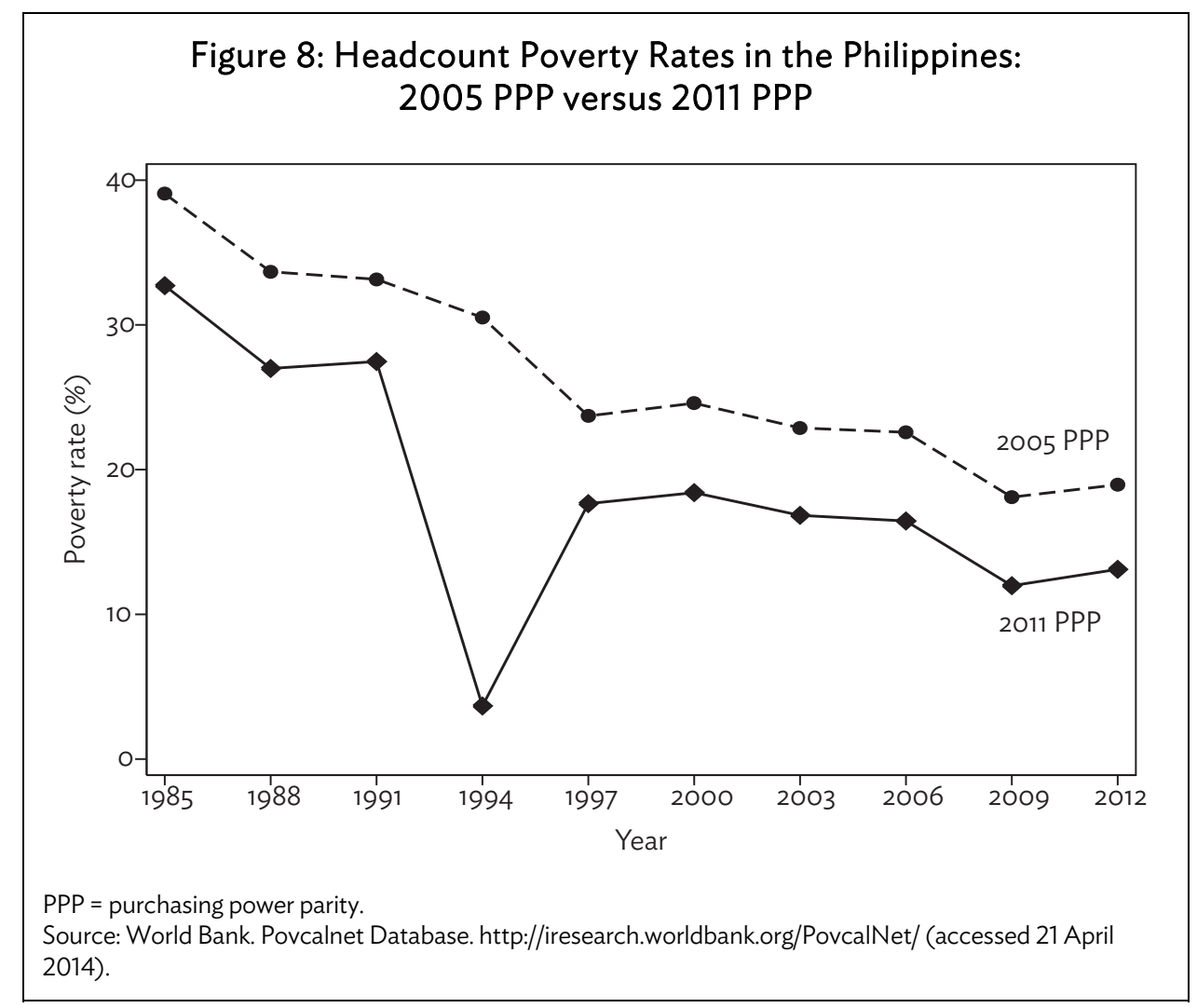

shorter work hours. The authors attribute it to the propensity of the migrant's relatives to substitute income-generating activities for more leisure.

19 The significant difference between the 2005 PPP-based estimates for 1994 is subject for further investigation. 
Table 5: Poverty Spells: 2005 PPP versus 2011 PPP

\begin{tabular}{|c|c|c|}
\hline \multirow[b]{2}{*}{$\begin{array}{l}\text { Poverty Status } \\
(2003,2006,2009)\end{array}$} & \multicolumn{2}{|c|}{ Proportion of Population (\%) } \\
\hline & $\begin{array}{c}2005 \text { PPP ( } \$ 1.25 \\
\text { Poverty Line) }\end{array}$ & $\begin{array}{c}2011 \text { PPP ( } \$ 1.9 \\
\text { Poverty Line) }\end{array}$ \\
\hline$P, P, P$ & 7.75 & 5.60 \\
\hline$P, P, N P$ & 4.55 & 4.31 \\
\hline$P, N P, P$ & 1.29 & 1.03 \\
\hline$P, N P, N P$ & 4.70 & 5.18 \\
\hline$N P, P, P$ & 2.97 & 2.34 \\
\hline$N P, P, N P$ & 3.98 & 3.71 \\
\hline$N P, N P, P$ & 3.38 & 2.41 \\
\hline$N P, N P, N P$ & 71.37 & 75.43 \\
\hline
\end{tabular}

$\mathrm{NP}=$ nonpoor, $\mathrm{P}=$ poor, $\mathrm{PPP}=$ purchasing power parity.

Source: Author's computations using longitudinal subsample of FIES.

\section{SUMMARY}

The examination of household panel data in the Philippines reveals that despite faster economic growth over the past decade, poverty remains a prominent feature of its development landscape. In particular, while about 40\% of the population were poor at any given (survey) year between 2003 and 2009 , estimates suggest that about 30\% were poor in all (survey) years examined, while 60\% experienced poverty at least once based on the $\$ 2$-a-day poverty threshold. Overall, this suggests a more dynamic poverty phenomenon in the country than what is conventionally perceived when examination is only based on trends in cross-sectional indicators of poverty.

To be able to respond to the challenge of reconciling stronger economic growth with positive gains in poverty reduction, it is important to implement policies that can minimize both persistent and transient forms of poverty. However, this calls for a different mix of policies. This prompts the need to address the question: Is poverty in the Philippines characterized by persistent or transient income shortfall? Consistent with the findings of Reyes et al. (2011) and Bayudan-Dacuycuy and Lim (2013), the results presented in this study suggest that most poverty experiences of Filipino households were persistent. In other words, households tended to stay in poverty for extended periods of time. This implies that poverty reduction programs should be aimed primarily at providing long-term human capital development. At the same time, there is also a need to create more high-quality jobs that can lift people out of persistent poverty. Nevertheless, the robustness analysis revealed that the relative importance of persistent and transient poverty were sensitive to the type of poverty measure used and the poverty line specified. In particular, the relative importance of transient poverty increased dramatically as the poverty line decreased or as the poverty measure becomes more sensitive to the illfare of the poorest of the poor. Given that the official poverty lines in the Philippines are lower compared to international poverty lines such as the $\$ 2 /$ day, the persistent and transient poverty rankings should be interpreted with caution. Another important finding of this study is that while persistent poverty tends to be highest in areas where overall poverty levels are highest, examination of poverty dynamics still contributes something to poverty analysis derived from cross-sectional data because it allows us to identify areas where the levels of transient poverty are significant. 
Understanding transient poverty and more generally, vulnerability to poverty, is important because the policy interventions needed to address this problem could be very different from that of persistent poverty. To be able to understand poverty vulnerability in the Philippines better, future research may use the concept of fuzzy logic (Lemmi and Betti 2006) or construct poverty vulnerability lines such as those proposed by Dang and Lanjouw (2014).

In conclusion, the results can be used to illuminate several important broad policy implications. First, an insignificant change in the cross-sectional estimates of poverty from 2003 to 2009 does not imply that all poor households were systematically excluded from reaping the benefits of the faster economic growth that transpired during this period. In particular, about $15 \%$ to $20 \%$ of the households classified as poor in an initial time period managed to escape poverty in the succeeding survey wave. Nevertheless, the risks of falling into poverty were also not trivial. For instance, about $10 \%$ to $15 \%$ of the initially nonpoor households fell into poverty in the succeeding wave. In other words, transition from poverty to nonpoverty does not necessarily imply a permanent escape from socioeconomic dearth. This means that existing social protection systems should be improved to minimize the adverse consequences of income shocks for both the poor and economically vulnerable. Second, for about 15\% to $40 \%$ of the population, poverty has been a long episode of socioeconomic deprivation. A more aggressive policy intervention is needed for these persistently poor households. One of the first steps might be to institutionalize an effective targeting system that will identify persistently poor households. Equally important is to ensure that intervention programs are accessible as many of these chronically poor households are likely situated in remote and hard-to-reach areas. Third, it is also important to create an economic environment that will encourage higher investments that will generate high-quality jobs and promote greater productivity, particularly in the nonagriculture sector. Lastly, the results emphasize that poverty in the Philippines is a heterogeneous phenomenon. The magnitude of persistent and transient poverty depends on the methodology used, thus, both types of deprivation should be of concern for socioeconomic planners in the Philippines. Poverty intervention programs should be tailored according to the heterogeneous needs or circumstances of the persistently and transiently poor in the Philippines. Overall, this study highlights the importance of collecting longitudinal data to measure poverty and social exclusion. In addition, the results of this study call for a balanced policy program that combines provision of social safety nets for stabilizing income flows and long-term development of human capital by improving the quality of education. 


\section{REFERENCES*}

Adair, L., D. Guile, E. Disprove, and S. Galliano. 2002. Effect of Childbearing on Filipino Women's Work Hours and Earnings. Journal of Population Economics. 15 (4). pp. 625-45.

Addawe, J., A. Martinez, and R. Perez. 2007. Responding to the Needs for Decentralized Planning: Small Area Poverty Estimates. Proceedings of the $10^{\text {th }}$ National Convention on Statistics. Manila. 1-2 October.

Ang, A., G. Sugiyarto, and S. Jha. 2009. Remittances and Household Behaviour in the Philippines. ADB Economics Working Paper Series No. 188. Manila: Asian Development Bank.

Asian Development Bank (ADB). 2005. Poverty in the Philippines: Income, Assets and Access. Manila.

2009. Poverty in the Philippines: Causes, Constraints and Opportunities. Manila.

Balisacan, A. 2002. The Rural Road to Poverty Reduction: Some Lessons from the Philippine Experience. Journal of Asian and African Studies. 37(2). pp. 147-67.

Bane, M., and D. Ellwood. 1986. Slipping Into and Out of Poverty: The Dynamics of Spells. Journal of Human Resources. 21 (1). pp. 1-23.

Banerjee, A., and E. Duflo. 2007. The Economic Lives of the Poor. Journal of Economic Perspectives. 21 (1). pp. 141-68.

Bayudan-Dacuycuy, C., and J. Lim. 2013. Chronic and Transient Poverty and Vulnerability to Poverty in the Philippines: Evidence Using a Simple Spells Approach. Social Indicators Research. 118. pp. 389-413. Doi:10.1007/s11205-013-0409-5.

Bersales, L. 2009. Issues on the Official Poverty Estimation Methodology in the Philippines: Comparability of Estimates across Space and over Time. Philippine Institute for Development Studies Discussion Paper No. 17.

Bigman, D., and H. Fofack. 2000. Geographical Targeting for Poverty Alleviation: An Introduction to the Special Issue. The World Bank Economic Review. 14 (1). pp. 129-45.

Brown, R., and G. Leeves. 2011. Comparative Effects of Migrants' Remittances on Composition of Recipient Household Income in Two small, Island Economies. Applied Economics. 43 (27). pp. 3965-76.

Christiaensen, L., and A. Shorrocks. 2012. Measuring Poverty over Time. Journal of Economic Inequality. 10 (2). pp. 137-67.

Committee on the Elimination of Discrimination Against Women (CEDAW). 2009. CEDAW in Action in Southeast Asia: Philippines. Retrieved 09/03, 2014. http://cedaw-seasia.org/philippines.html

\footnotetext{
*ADB recognizes "China” as the People's Republic of China.
} 
Conley, D. 2000. Sibling Sex Composition: Effects on Educational Attainment. Social Science Research. 29. pp. 441-57.

Dang, H., and Lanjouw, P. 2014. Welfare Dynamics Measurement: Two Definitions of a Vulnerability Line and Their Empirical Application. World Bank Policy Research Paper No. 6994. Washington, DC: World Bank.

Duclos, J., A. Araar, and A. Giles. 2010. Chronic and Transient Poverty: Measurement and Estimation, with Evidence from China. Journal of Development Economics. 91 (2). pp. 266-77.

Elbers, C., J. Lanjouw, and P. Lanjouw. 2003. Micro-level Estimation of Poverty and Inequality. Econometrica. 71 (1).pp. 355-64.

Ericta, C., and E. Fabian. 2009. A Documentation of the Philippines' Family Income and Expenditure Survey. Philippine Institute for Development Studies Discussion Paper No. 18.

Felipe, J., and L. Lanzona. 2006. Unemployment, Labor Laws, and Economic Policies in the Philippines. In J. Felipe and R. Hasan, eds. Labor Markets in Asia-Issues and Perspectives. New York: Asian Development Bank / Palgrave Macmillan.

Foster, J. 2009. A Class of Chronic Poverty Measures. In T. Addison, D. Hulme, and R. Kanbur, eds. Poverty Dynamics: Interdisciplinary Perspectives, pp. 59-76. Oxford: Oxford University Press.

Foster, J., J. Greer, and E. Thorbecke. 1984. A Class of Decomposable Poverty Measures. Econometrica, 52 (3). pp. 761-66.

Foster, J., S. Seth, M. Lokshin, and Z. Sajaia, eds. 2013. A Unified Approach to Measuring Poverty and Inequality: Theory and Practice. Washington, DC: World Bank. doi:doi/book/10.1596/978-08213-8461-9

Friedman, M. 1957. The Permanent Income Yypothesis. In M. Friedman, ed. A Theory of the Consumption Function, pp. 20-37. Princeton University Press.

Gaiha, R., and A. Deolalikar. 1993. Persistent, Expected and Innate Poverty: Estimates for Semi-arid Rural India, 1974-1984. Cambridge Journal of Economics. 17 (4). pp. 409-21.

Gottschalk, P. 1982. Earnings Mobility: Permanent Change or Transitory Fluctuations? The Review of Economics and Statistics. 64 (3). pp. 450-56.

Gradin, C., and C. del Rio. 2012. Measuring Poverty Accounting for Time. Review of Income and Wealth. 58 (2). pp. 330-54.

Hasan, R., and K. Jandoc. 2010. Workers' Earnings in the Philippines: Comparing Self-employment with Wage Employment. Asian Development Review. 27 (1). pp. 43-79.

Haughton, J., and S. Khandker. 2009. Handbook on Poverty and Inequality. World Bank. doi:10.1596/978-0-8213-7613-3. 
Hennigner, N., and M. Snel. 2002. Where are the Poor? Experiences with the Development and Use of Poverty Maps. Washington, DC: World Resources Institute and Norway: UNEP/GRID-Arendal.

Housing and Urban Development Coordinating Council. 2008. Metro Manila Road Map for Urban Renewal and Basic Services for the Poor.

Jalan, J., and M. Ravallion. 1998. Transient Poverty in Post-Reform Rural China. Journal of Comparative Economics. 26 (2). pp. 338-57.

Jappelli, T. 1990. Who is Credit Constrained in the US Economy. Quarterly Journal of Economics. 105 (1). pp. 219-34.

Kanbur, R. 1987. Measurement and Alleviation of Poverty: With an Application to the Impact of Macroeconomic Adjustment. International Monetary Fund Staff Papers. 34 (1). pp. 60-85.

Lemmi, A., and G. Betti. 2006. Fuzzy Set Approach to Multidimensional Poverty Measurement. New York: Springer.

Martinez, A. 2012. Small Area Estimation with a Multivariate Spatial-Temporal Model. The Philippine Statistician. 61 (2). pp. 1-17.

McCulloch, N., and B. Baulch. 1999. Distinguishing the Chronically from the Transitorily Poor: Evidence from Rural Pakistan. Institute of Development Studies Working Paper No. 97. University of Sussex.

National Statistical Coordination Board (NSCB). 2012. Fishermen still the Poorest Sector in 2009. NSCB Press Release on Official Poverty Statistics for the Basic Sectors. http://www.nscb.gov.ph/pressreleases/2012/PR-201206-SS2-01_pov2009.asp

- 2013. Poverty Incidence Unchanged, as of First Semester 2012. NSCB Press Release. http://www.nscb.gov.ph/poverty/defaultnews.asp

Pernia, E. 2008. Migration, Remittances, Poverty and Inequality in the Philippines. University of the Philippines School of Economics Discussion Papers 01.

Philippine Atmospheric Geophysical and Astronomical Services Administration (PAG-ASA). 2013. PAG-ASA Database. www.pagasa.dost.gov.ph (accessed November 2013).

Philippine Statistics Authority (PSA). Family Income and Expenditure Survey (FIES). 2003, 2006, 2009. Microdata provided by the PSA.

Ravallion, M., and J. Jalan. 1996. Growth Divergence Due to Spatial Externalities. Economic Letters. 53 (2). pp. 227-32.

Ravallion, M., and Q. Wodon. 1997. Poor Areas or only Poor People? World Bank Policy Research Working Paper No. 1798.

Reyes, C. 2002. Impact of Agrarian Reform on Poverty. Philippine Journal of Development. 29 (2). pp. 63-131. 
Reyes, C., and A. Tabuga. 2012. Conditional Cash Program in the Philippines: Is It Reaching the Extremely Poor. Philippine Institute for Development Studies No. 42.

Reyes, C., A. Tabuga, C. Mina, R. Asis, and M. Datu. 2011. Dynamics of Poverty in the Philippines: Distinguishing the Chronic from the Transient Poor. Philippine Institute for Development Studies Discussion Paper No. 31.

Rodriguez, E., and E. Tiongson. 2001. Temporary Migration Overseas and Household Labor Supply: Evidence from Urban Philippines. International Migration Review. 35 (3). pp. 709-25.

Sta. Ana, S., and E. Varona. 2012. Computation of Spatial Index for the Poor. Manila: Southeast Asian Regional Centre for Graduate Study and Research in Agriculture and National Statistics Office.

Tilak, J. 2002. Higher Education under Structural adjustment. In P. Banerjee and F. Richter, eds. Economic Institutions in India, pp. 289-341. Palgrave Macmillan.

World Bank. Povcalnet Database. http://iresearch.worldbank.org/PovcalNet/

- World Development Indicators (WDI) 2013 Database. http://data.worldbank.org/datacatalog/world-development-indicators (accessed 3 September 2013). 


\section{Analytical Tools for Measuring Poverty Dynamics: An Application Using Panel Data in the Philippines}

The Philippines has experienced rapid economic growth over the past decade. However, the benefits of economic expansion have not resulted to significant poverty reduction. This paper aims to measure poverty dynamics and identify the correlates of chronic and transient poverty in the Philippines.

\section{About the Asian Development Bank}

ADB's vision is an Asia and Pacific region free of poverty. Its mission is to help its developing member countries reduce poverty and improve the quality of life of their people. Despite the region's many successes, it remains home to the majority of the world's poor. ADB is committed to reducing poverty through inclusive economic growth, environmentally sustainable growth, and regional integration.

Based in Manila, ADB is owned by 67 members, including 48 from the region. Its main instruments for helping its developing member countries are policy dialogue, loans, equity investments, guarantees, grants, and technical assistance.

$\mathrm{ADB}$ 